\title{
Policy change and learning in the RBC model
}

\author{
Kaushik Mitra $^{\mathrm{a}, *}$, George W. Evans ${ }^{\mathrm{a}, \mathrm{b}}$, Seppo Honkapohja ${ }^{\mathrm{c}}$ \\ a School of Economics E Finance, University of St Andrews, Castlecliffe, The Scores, St Andrews, Fife KY169AL, UK \\ ${ }^{\mathrm{b}}$ University of Oregon, Oregon, United States \\ ${ }^{\mathrm{c}}$ Bank of Finland, Finland
}

\section{A R T I C L E I N F O}

\section{Article history:}

Received 24 January 2012

Accepted 19 April 2013

Available online 23 May 2013

JEL classification:

E62

D84

E21

E43

Keywords:

Taxation

Government spending

Expectations

Permanent policy changes

\begin{abstract}
A B S T R A C T
What is the impact of surprise and anticipated policy changes when agents form expectations using adaptive learning rather than rational expectations? We examine this issue using the standard stochastic real business cycle model with lump-sum taxes. Agents combine knowledge about future policy with econometric forecasts of future wages and interest rates. Dynamics under learning can have large impact effects and a gradual hump-shaped response, and tend to be prominently characterized by oscillations not present under rational expectations. These fluctuations reflect periods of excessive optimism or pessimism, followed by subsequent corrections.
\end{abstract}

(c) 2013 Elsevier B.V. All rights reserved.

\section{Introduction}

Typically economic models are analyzed with an unchanged structure. In practice, policy changes take place, and these often involve long delays. In the case of fiscal policy these lags sometimes exceed two years. The process of changing taxes involves legislative lags, between when the new tax is proposed and when it is passed, and implementation lags, between when the legislation is signed into law and when it actually takes effect. These changes in policy may well be anticipated by economic actors and will influence decisions even before the actual implementation of the proposed policy change. ${ }^{1}$

The standard assumption in macroeconomics is, of course, rational expectations (RE), and this has been used to analyze the impact of both surprise and preannounced policy changes. Within a nonstochastic perfect foresight setting, see for example, Sargent and Wallace (1973), Blanchard and Fischer (1989), Romer (2011) and Ljungqvist and Sargent (2012). The seminal contributions of Baxter and King (1993) and Aiyagari et al. (1992) analyze changes to fiscal policy within a RE framework in the stochastic real business cycle (RBC) model. ${ }^{2}$

However, the benchmark assumption of RE is very strong and arguably unrealistic when analyzing the effect of policy changes. Agents need to have complete knowledge of the underlying structure, both before and after the policy change.

\footnotetext{
* Corresponding author. Tel.: + 441334 461951; fax: +44 1334462444.

E-mail addresses: Kaushik.Mitra@standrews.ac.uk, km91@st-andrews.ac.uk (K. Mitra).

1 Active fiscal strategies have been adopted in various countries around the world (like in the US and UK) in the wake of the recent "Great Recession". These measures include temporary tax cuts and credits and large public works projects; see for instance Auerbach et al. (2010).

2 There has been a recent large literature on the effects of anticipated changes in policy. We comment on this literature in Section 5.
} 
They must also rationally and fully incorporate this knowledge in their decision making, and do so under the assumption that other agents are equally knowledgeable and equally rational.

Recently there has been increasing interest in studying situations in which agents have incomplete knowledge of the economy. The assumption that economic agents engage in "learning" behavior has been incorporated into macroeconomic theory (see e.g. Sargent, 1993 and Evans and Honkapohja, 2001) and used in a wide range of applications in macroeconomics and finance. The standard adaptive learning approach treats economic agents like econometricians who estimate forecast rules, updating the parameter estimates over time as new data become available. It has been shown that in many models, including the RBC model, least-squares learning can converge over time to the RE solution, while at the same time often providing plausible transitional dynamics that are arguably of empirical importance. ${ }^{3}$

However, analyses of learning typically assume an unchanged economic structure. ${ }^{4}$ An apparent drawback of leastsquares learning rules is that estimated coefficients respond relatively slowly to data, and thus standard learning rules take time to adjust to structural or policy changes. In some cases this is realistic, but in the case of clearly articulated policy changes one would expect even boundedly rational agents to incorporate structural information about future policy.

In this paper we show how to analyze fiscal policy changes in a learning framework for the stochastic RBC model. To do so we assume that agents forecast some key variables using adaptive learning, while simultaneously incorporating structural knowledge about future government spending and taxes. For reasons of space we focus on permanent policy changes, and the results are contrasted with those from the RE approach. ${ }^{5}$ One case we consider in detail is the impact of announced future policy changes.

The question of how to analyze known structural changes in a learning framework was taken up in Evans et al. (2009). They considered announced changes in fiscal policy in a simple endowment economy model and (briefly) in a Ramsey model. However, a major limitation of their framework was its deterministic nature which consequently restricted the type of learning behavior that could be analyzed. ${ }^{6}$ In addition, the variable labor supply assumption in the RBC model plays a crucial role in the policy analysis of government spending by Baxter and King (1993).

Our approach uses an adaptive learning model in which agents in effect also have partial structural knowledge. At each moment in time agents must make consumption and labor supply decisions based on the time path of expected future wages, interest rates and taxes. As is standard with adaptive learning, we assume that agents make forecasts of wages and interest rates based on a statistical model, with coefficients updated over time using least-squares. However, for forecasting future taxes we assume that agents use the path of future taxes announced (credibly) by policymakers. ${ }^{7}$

This approach seems to us very natural. The essence of the adaptive learning approach is that agents are assumed not to understand the general equilibrium considerations that govern the evolution of the central endogenous variables, i.e. capital, labor and factor prices. Agents are therefore assumed to forecast these variables statistically. On the other hand, agents can be expected to immediately incorporate their decisions about the direct effects on their future net incomes of the announced path of future taxes. As noted in Evans et al. (2009), this general approach to combining statistical learning and limited structural knowledge can be adapted to other economic situations.

Several general features stand out in our analysis of fiscal policy changes in the RBC model. As under RE, announced current or future changes in government spending leads to immediate changes in consumption, employment, and output. ${ }^{8}$ However, with adaptive learning the solution exhibits hump-shaped responses and oscillatory convergence to the new steady state, including overshooting not present under RE. These dynamics stem from a combination of inertia in capital accumulation and the adaptation of expectations to data generated by the learning rules used by private agents.

We also show that impact effects of policy changes, announced to take place in the future, can be more extreme under learning than under RE, because the wealth effects of future tax changes are immediate, while partly offsetting price effects are spread out over time and unknown to agents.

A final important feature of the model under learning dynamics is that policy changes can lead to systematic waves of optimism or pessimism. The details depend naturally on the type of policy change considered. For example, a permanent increase in government spending, announced to take place in the future, generates a period of over-optimism concerning wages during much of the pre-implementation period, followed by a correction during the post-implementation period. Such periods of over-optimism or over-pessimism reflect general equilibrium effects, and are a consequence of the agents's incomplete structural knowledge.

Section 2 below describes the basic RBC model in the presence of learning by agents. Section 3 analyzes permanent changes in policy both within a RE framework and under learning. Section 4 looks at the robustness of our results, including alternative assumptions about agents beliefs. Section 5 relates our approach to the recent literature on fiscal and news shocks. The final section concludes.

\footnotetext{
3 See Sargent (2008) and Evans and Honkapohja (2013) for extensive references.

4 See, however, Evans et al. (2001), Marcet and Nicolini (2003) and Giannitsarou (2006) for partial exceptions.

5 Temporary policy changes are considered in the working paper version of this paper (Mitra et al., 2011), and their policy implications are examined in Mitra et al. (2012)

${ }^{6}$ For a discussion of the differences of learning in deterministic and stochastic models, see Evans and Honkapohja (1998).

7 For convenience we assume a balanced budget, so that in each period taxes equal government spending.

${ }^{8}$ Surprisingly, it appears that announced future changes of government spending have not previously been systematically studied under RE for the stochastic RBC model.
} 


\section{The model}

There is a representative household who has preferences over non-negative streams of a single consumption good $c_{t}$ and leisure $1-n_{t}$ given by

$$
\hat{E}_{t}\left\{\sum_{s=t}^{\infty} \beta^{s-t} U\left(c_{s}, 1-n_{s}\right)\right\} .
$$

Here $\hat{E}_{t}$ denotes potentially subjective expectations at time $t$ for the future, which agents hold in the absence of rational expectations. The analysis of the model under RE is standard. When RE is assumed we indicate this by writing $E_{t}$ for $\hat{E}_{t}$. Our presentation of the model is general in the sense that it applies under learning as well as under RE.

We assume the general form

$$
U\left(c_{s}, 1-n_{s}\right)=\frac{c_{s}^{1-\sigma}}{1-\sigma}+\zeta \frac{\left(1-n_{s}\right)^{1-\epsilon}}{1-\epsilon}
$$

for $\sigma, \epsilon, \zeta>0$, and often focus on the widely considered special case, $\sigma=\epsilon=1$, i.e. $U\left(c_{s}, 1-n_{s}\right)=\ln c_{s}+\zeta \ln \left(1-n_{s}\right)$ as in Ljungqvist and Sargent (2012, p. 376), Long and Plosser (1983) and McCallum (1989). ${ }^{9}$

The household flow budget constraint is

$$
\begin{aligned}
& a_{t+1}=w_{t} n_{t}+r_{t} a_{t}-c_{t}-\tau_{h, t} \quad \text { where } \\
& r_{t}=1-\delta+r_{k, t} .
\end{aligned}
$$

Here $a_{t}$ is per capita household wealth at the beginning of time $t$, which equals holdings of capital $k_{t}$ owned by the household less their debt (to other households), $b_{p t}$, i.e. $a_{t} \equiv k_{t}-b_{p t} . r_{t}$ is the gross interest rate for loans made to other households, $w_{t}$ is the wage rate, $c_{t}$ is consumption, $n_{t}$ is labor supply and $\tau_{h, t}$ is per capita lump sum taxes. Eq. (4) arises due to the absence of arbitrage from loans and capital being perfect substitutes as stores of value; $r_{k, t}$ is the rental rate on capital goods and $\delta$ is the depreciation rate.

Households maximize utility (1) subject to the budget constraint (3) which yields the Euler equation for consumption

$$
c_{t}^{-\sigma}=\beta \hat{E}_{t} r_{t+1} c_{t+1}^{-\sigma}
$$

We next derive the (linearized) consumption function.

From the flow budget constraint (3) we can get the intertemporal budget constraint (in realized terms)

$$
0=r_{t} a_{t}+\sum_{j=1}^{\infty}\left(D_{t, t+j}(t)\right)^{-1} \chi_{t+j}+\chi_{t}
$$

where

$$
D_{t, t+j}=\prod_{i=1}^{j} r_{t+i}, \quad j \geq 1 \quad \text { and } \quad \chi_{t} \equiv w_{t} n_{t}-c_{t}-\tau_{h, t}
$$

by assuming the condition $D_{t, t+j}^{-1} a_{t+j+1} \rightarrow 0$ as $j \rightarrow \infty$ holds (which is obtained by combining the transversality and the noponzi game conditions).

Note that (6) involves future choices of labor supply by the household which we next eliminate to derive the linearized consumption function. For this we make use of the static first order condition (between consumption and labor supply) from the household's problem which can be written as

$$
n_{t}=1-\zeta^{1 / \epsilon} c_{t}^{\sigma / \epsilon} w_{t}^{-(1 / \epsilon)}
$$

This gives a relationship between labor supply and consumption choices which can be used to substitute out $n_{t+j}$ in (6). Taking expectations we then get the expected value intertemporal budget constraint

$$
0=r_{t} a_{t}+\left(w_{t}-\zeta^{1 / \epsilon} c_{t}^{\sigma / \epsilon} w_{t}^{1-(1 / \epsilon)}-c_{t}-\tau_{h, t}\right)+\sum_{j=1}^{\infty} \hat{E}_{t}\left(D_{t, t+j}\right)^{-1}\left\{w_{t+j}-\zeta^{1 / \epsilon} c_{t+j}^{\sigma / \epsilon} w_{t+j}^{1-(1 / \epsilon)}-c_{t+j}-\tau_{h, t+j}\right\}
$$

To obtain its optimal choice of consumption $c_{t}$, we assume that the household uses a consumption function based on a linearization around steady state values. In particular, we assume that agents linearize the expected value intertemporal budget constraint and the Euler equations around the initial steady state values $\bar{c}, \bar{a}, \bar{w}, \bar{\tau}_{h}$ and $\bar{r}=\beta^{-1}$. This is a natural choice since agents can be assumed to have estimated precisely the steady state values before the policy change that takes place. ${ }^{10}$

\footnotetext{
${ }^{9}$ As shown in King et al. (1988), log utility for consumption is needed for steady state labor supply along a balanced growth path. Campbell (1994, Section 3) uses (2) with $\sigma=1$.

10 Thus we assume that the final steady state values of $k, w$ and $r$ are not initially known to agents. Under least-squares learning agents will eventually come to know the new steady state values as happens in all of the simulations below. We remark that an alternative approach to our procedure would be to assume that agents also update over time the point around which the consumption function is linearized, with the sequence of linearization points chosen
} 
As shown in the Appendix, substituting the linearized Euler equations into the intertemporal budget constraint, we obtain the consumption function

$$
\left(c_{t}-\bar{c}\right) C_{A A}=\bar{a}\left(r_{t}-\bar{r}\right)+\beta^{-1}\left(a_{t}-\bar{a}\right)-\left(\tau_{h, t}-\bar{\tau}_{h}\right)+C_{w w}\left(w_{t}-\bar{w}\right)-C_{r r} S r_{t}^{e}-S \tau_{h, t}^{e}+C_{w w} S w_{t}^{e},
$$

where $C_{A A}, C_{w w}$ and $C_{r r}$ are given in the Appendix and where

$$
\begin{aligned}
& S r_{t}^{e} \equiv \sum_{j=1}^{\infty} \beta^{j+1} \sum_{i=1}^{j}\left(r_{t+i}^{e}-\bar{r}\right), \\
& S \tau_{h, t}^{e} \equiv \sum_{j=1}^{\infty} \beta^{j}\left(\tau_{h, t+j}^{e}-\bar{\tau}_{h}\right), \\
& S w_{t}^{e} \equiv \sum_{j=1}^{\infty} \beta^{j}\left(w_{t+j}^{e}-\bar{w}\right),
\end{aligned}
$$

denote "present value" type expressions.

Eq. (8) specifies a behavioral rule for the household's choice of current consumption based on pre-determined values of initial assets, real interest rates, wage rates, current values of lump-sum taxes and (subjective) expectations of future values of wages, interest rates, and lump-sum taxes. Expectations are assumed to be formed at the beginning of period $t$ and, for simplicity, we assume these to be identical across agents (though agents themselves do not know this to be the case). Eq. (8) can then be viewed as the behavioral rule for per capita consumption in the economy. Note that $c_{t}, n_{t}$ and $w_{t}$ are simultaneously determined given expectations.

To implement the behavioral rule, however, the household requires forecasts $r_{t+i}^{e}, w_{t+j}^{e}$, and $\tau_{h, t+j}^{e}$. For taxes $\tau_{h, t+j}^{e}$ (and $\bar{\tau}_{h}$ ) we assume that agents use "structural" knowledge based on announced government spending rules. For convenience we assume balanced budgets, so that $\tau_{h, t+j}=g_{t+j} \cdot{ }^{11}$ For $r_{t+i}^{e}$ and $w_{t+j}^{e}$ we assume households estimate future values using a VAR-type model in $k_{t}, w_{t}, r_{k, t}$ and $v_{t}$, with coefficients updated over time by recursive least squares (RLS). The detailed procedure is described in Section 3.1.

Linearizing Eq. (7) we also obtain the employment equation, which will be useful later

$$
n_{t}-\bar{n}=-\frac{\sigma}{\epsilon} \zeta^{1 / \epsilon}(\bar{W})^{-\frac{1}{\epsilon} \bar{C}^{\frac{\sigma}{e}}-1}\left(c_{t}-\bar{C}\right)+\frac{1}{\bar{W} \epsilon} \zeta^{1 / \epsilon}(\bar{W})^{-1 / \epsilon} \bar{c}^{\sigma / \epsilon}\left(w_{t}-\bar{W}\right)
$$

To complete the model, we describe the evolution of the other state variables, namely $w_{t}, r_{k, t}, r_{t}, y_{t}$ and $k_{t+1}$. Households own capital and labor services which they rent to firms. The firm uses these inputs to produce output $y_{t}$ using the CobbDouglas production technology

$$
y_{t}=v_{t} k_{t}^{\alpha} n_{t}^{1-\alpha}
$$

where $v_{t}$ is the technology shock that follows an $\operatorname{AR}(1)$ process

$$
\hat{v}_{t}=\rho \hat{v}_{t-1}+\tilde{u}_{t},
$$

with $\hat{v}_{t}=\left(v_{t}-\bar{v}\right)$. Here $\bar{v}$ is the mean of the process and $\tilde{u}_{t}$ is an iid zero-mean process with constant variance $\sigma_{u}^{2}{ }^{12}$

Profit maximization by firms implies the standard first-order conditions involving wages and rental rates

$$
w_{t}=(1-\alpha) v_{t}\left(\frac{k_{t}}{n_{t}}\right)^{\alpha} \quad \text { and } \quad r_{k, t}=\alpha v_{t}\left(\frac{n_{t}}{k_{t}}\right)^{1-\alpha} \text {. }
$$

In equilibrium, aggregate private debt $b_{p t}$ is zero, so that $a_{t}=k_{t}$, and market clearing determines $k_{t+1}$ from

$$
k_{t+1}=v_{t} k_{t}^{\alpha} n_{t}^{1-\alpha}+(1-\delta) k_{t}-c_{t}-g_{t},
$$

where $g_{t}$ is per capita government spending.

For simulations of the model we follow standard procedures and approximate the path using a linearization around the steady state. ${ }^{13}$ The linearized equations for the wage rate, rental rate, real interest rate, output and capital accumulation equations, together with the equations giving the steady state, are given in the Appendix.

\footnotetext{
(footnote continued)

to be consistent with the agent's estimates of the new steady-state values. Provided the changes in government spending are not too large, it is satisfactory to use our simpler procedure of using a fixed linearization point.

11 Balanced budgets are not as restrictive as it may appear, since under suitable assumptions Ricardian equivalence can continue to hold under adaptive learning. See Evans et al. (2012).

12 For simplicity we do not include a trend in technical progress. This would be straightforward to add, but doing so would require choosing between a deterministic and a stochastic trend, and it would substantially complicate the presentation.

${ }^{13}$ It is also straightforward to simulate the model under learning using the exact (nonlinear) equations for $y_{t}, w_{t}, r_{k, t}, r_{t}$ and $k_{t+1}$. For the model at hand we have found the results for the two methods to be very similar. Simulations using linear approximations are much faster, however, so we have used these in the reported results.
} 
To examine the impact of policy in the model under learning, we will compare the dynamics to those under RE. In the absence of a policy change, under RE the endogenous variables, $k_{t+1}, c_{t}, n_{t}, w_{t}, r_{k, t}, r_{t}$, can be written as approximate linear function of $k_{t}$ and $v_{t}$, e.g. Campbell (1994). In particular

$$
\begin{aligned}
& \hat{k}_{t+1}=\lambda_{2} \hat{k}_{t}+f_{k v} \hat{v}_{t}, \\
& \hat{w}_{t}=f_{w k} \hat{k}_{t}+f_{w v} \hat{v}_{t}, \\
& \hat{r}_{k, t}=f_{r k} \hat{k}_{t}+f_{r v} \hat{v}_{t},
\end{aligned}
$$

where the hatted values are deviations from the RE deterministic steady state, i.e. $\hat{k}_{t}=k_{t}-\bar{k}, \hat{r}_{k, t}=r_{k, t}-\bar{r}_{k}, \hat{w}_{t}=w_{t}-\bar{w}$, etc. The RE solution takes the form of a stationary $\operatorname{VAR}(1)$ in the state $\hat{x}_{t} \equiv\left(\begin{array}{l}\hat{k}_{t} \\ \hat{v}_{t}\end{array}\right)$

$$
\begin{aligned}
& \left(\begin{array}{l}
\hat{k}_{t+1} \\
\hat{v}_{t+1}
\end{array}\right)=B\left(\begin{array}{l}
\hat{k}_{t} \\
\hat{v}_{t}
\end{array}\right)+\left(\begin{array}{l}
0 \\
1
\end{array}\right) \tilde{u}_{t+1}, \\
& B=\left(\begin{array}{cc}
\lambda_{2} & f_{k v} \\
0 & \rho
\end{array}\right),
\end{aligned}
$$

with the other variables given by linear combinations of the state. Note also that under RE forecasts of future $\hat{w}_{t+j}$ and $\hat{r}_{k, t+j}$ are given by linear combinations of the forecasted future state $\hat{x}_{t+j}^{e}=B^{j} \hat{x}_{t}$.

We now turn to obtaining the dynamics, under both RE and learning, when there is a policy change.

\section{Permanent policy changes}

At the beginning of period $t=1$, a policy announcement is made that the level of government spending will change permanently upward from $\bar{g}$ to $\bar{g}^{\prime}$ at a specified date $T_{p}$ in the future. The policy announcement is assumed to be credible and known to the agents with certainty. With a balanced budget, this means equivalently that there is an anticipated change in (per capita) taxes, i.e. $\tau_{h, t}=\bar{\tau}=\bar{g}$ when $t<T_{p}$ and $\tau_{h, t}=\bar{\tau}^{\prime}=\bar{g}^{\prime}$ when $t \geq T_{p}$.

The long run effects on the steady state of an increase in government expenditure are well-known, e.g. Baxter and King (1993). The new steady state involves lower consumption and higher levels of investment, output, labor, and capital, but an unchanged capital-labor ratio. The latter implies that steady state wages and interest rates are unchanged. The method for obtaining the impact of policy changes under RE is standard, see Appendix C for the details.

\subsection{Learning dynamics}

We now consider the learning dynamics in the context of the policy change just described. In the standard adaptive learning approach, private agents would formulate an econometric model to forecast future taxes as well as interest rates and wage rates, since these are required in order for agents to solve for their optimal level of consumption. We continue to follow this approach with respect to interest rates and wage rates, but take the radically different approach for forecasting taxes by assuming that agents understand the future course of taxes implied by the announced policy. In effect, we are giving the agents structural knowledge of one part of the economy: the fiscal implications of the announced future change in government spending. ${ }^{14}$

As argued in the Introduction, we think this is a natural way to proceed, since changes in agents' own future taxes have a quantifiable direct effect, while future wages and interest rates are determined through dynamic general equilibrium effects. The adaptive learning perspective is that it is unrealistic to assume that agents understand the economic structure sufficiently well to improve on reduced form econometric forecasts of aggregate variables like wages and interest rates.

To keep things simple, we assume that the government operates and is known to operate under a balanced-budget rule. Given this structural knowledge of the government budget constraint and the announced path of government spending, the agents can thus use $\bar{\tau}=\bar{g}$, for $t<T_{p}$, and $\bar{\tau}^{\prime}=\bar{g}^{\prime}$, for $t \geq T_{p}$, for their forecasts of future taxes. Of course, for simplicity we are assuming that the announced policy change is fully credible. It would be possible to relax this assumption within the general framework of our approach.

Since the path of future taxes $\tau_{t+j}=g_{t+j}$ is known to agents, they compute its present value as

$$
S \tau_{h, t}^{e}=\sum_{j=1}^{\infty} \beta^{j}\left(g_{t+j}-\bar{g}\right)= \begin{cases}\frac{\beta^{T_{p}-t+1}}{1-\beta}\left(\bar{g}^{\prime}-\bar{g}\right), & 1 \leq t \leq T_{p}-1 \\ \frac{\beta}{1-\beta}\left(\bar{g}^{\prime}-\bar{g}\right), & t \geq T_{p} .\end{cases}
$$

\footnotetext{
${ }^{14}$ A related approach is followed in Preston (2006) and Eusepi and Preston (2010) in connection with monetary policy: in some cases agents are assumed to incorporate the announced interest-rate rule in their forecasts.
} 
However, under learning, agents still need to form forecasts of future wages and interest rates since these are needed for their individual consumption choice in (8).

Under RE, agents are assumed to know all the underlying parameters involved in the REE solution, i.e. the parameters in (14)-(16), which they use to form future forecasts of wages and rental rates. For anticipated changes in policy the implicit assumptions under RE are even stronger: agents need to know the full structural model and use it to deduce the full equilibrium path that puts the economy on the new saddle path at the exact time at which the policy change takes place. Furthermore this computation by agents must be made under the assumption that other agents are equally "rational" and make the same computation. From the learning perspective, these assumptions are implausibly strong and hence unrealistic.

Under learning wage and interest rate forecasts depend on the perceived laws of motion (PLMs) of the agents, with parameters updated over time in response to the data. We consider PLMs given by (13)-(15) in which future capital, wages, and rental rates depend on the current capital stock and technological shock, $k_{t}$ and $v_{t}$. That is, we consider PLMs that are of the form (including constants)

$$
\begin{aligned}
& k_{t+1}=b_{k}+a_{k k} k_{t}+a_{k v} \hat{v}_{t}+\text { noise }, \\
& w_{t}=b_{w}+a_{w k} k_{t}+a_{w v} \hat{v}_{t}+\text { noise, } \\
& r_{k, t}=b_{r}+a_{r k} k_{t}+a_{r v} \hat{v}_{t}+\text { noise }, \\
& \hat{v}_{t}=\rho \hat{v}_{t-1}+\tilde{u}_{t},
\end{aligned}
$$

where the PLM parameters $b_{k}, a_{k k}$ etc. will be estimated on the basis of actual data. The final line is the stochastic process for evolution of the (de-meaned) technological shock, which for simplicity is assumed known to the agents. In real-time learning, the parameters in (18)-(20) are time dependent and are updated using RLS; see for example [Evans and Honkapohja, 2001, p. 233]. We assume agents allow for structural change, which would include policy changes as well as other potential structural breaks, by discounting older data as discussed below.

In assuming that agents forecast using the PLM (18)-(21), we are implicitly assuming that they do not have useful information available from previous policy changes. We think this is generally plausible, since policy changes are relatively infrequent and since the qualitative and quantitative details of previous policy changes are unlikely to be the same. In particular, any previous fiscal policy changes, of the type considered here, are likely to have varied in terms of the magnitude and duration of the change in government spending, the extent to which it was anticipated, and the state of the economy in which it was announced and implemented. Since older information of this type would probably have limited value, we assume that agents respond to policy change by updating the parameters of the PLM (18)-(20) as new data become available. ${ }^{15}$

Before discussing how the PLM coefficients are updated over time using least-squares learning, we describe how (18)-(20) are used by agents to make forecasts. Given coefficient estimates and the observed state $\left(k_{t}, \hat{v}_{t}\right)$, Eqs. (18) and (21) can be iterated forward to obtain forecasts $k_{t+j}^{e}$ and $\hat{v}_{t+j}$ for $j=1,2, \ldots$. Wage and rental rate forecasts $w_{t+j}^{e}, r_{k, t+j}^{e}$ are then obtained using the relationships (19) and (20), with estimated coefficients, and interest-rate forecasts are given by $r_{t+j}^{e}=1-\delta+r_{k, t+j}^{e}$ using (4). Given these forecasts, $S w_{t}^{e}$ and $S r_{t}^{e}$ are computed from (11) and (9), which in turn are used in (8) to help determine consumption in the temporary equilibrium. For further details see the Appendix.

Parameter updating by agents using RLS learning is as follows. We define the time $t$ parameter estimates as

$$
\phi_{k, t}=\left(\begin{array}{c}
b_{k, t} \\
a_{k k, t} \\
a_{k v, t}
\end{array}\right), \quad \phi_{w, t}=\left(\begin{array}{c}
b_{w, t} \\
a_{w k, t} \\
a_{w v, t}
\end{array}\right), \quad \phi_{r k, t}=\left(\begin{array}{c}
b_{r, t} \\
a_{r k, t} \\
a_{r v, t}
\end{array}\right), \quad z_{t}=\left(\begin{array}{c}
1 \\
k_{t} \\
\hat{v}_{t}
\end{array}\right) .
$$

The RLS formulas corresponding to estimates of Eq. (18) then are

$$
\begin{aligned}
& \phi_{k, t}=\phi_{k, t-1}+\gamma R_{t}^{-1} z_{t-1}\left(k_{t}-\phi^{\prime}{ }_{k, t-1} z_{t-1}\right), \\
& R_{t}=R_{t-1}+\gamma\left(z_{t-1} z_{t-1}^{\prime}-R_{t-1}\right) .
\end{aligned}
$$

Here we are assuming that agents update parameter estimates using “discounted least squares," i.e. they discount past data geometrically at rate $1-\gamma$, where $0<\gamma<1$ is a (typically) small positive number. ${ }^{16}$ In the learning literature the parameter $\gamma$ is known as the "gain," and discounted least squares is also called "constant-gain" least squares. $\phi_{w, t}$ and $\phi_{r k, t}$ are estimated in the same way, see below.

Constant-gain least squares is widely used in the adaptive learning literature because it weights recent data more heavily. See for example Sargent (1999), Cho et al. (2002), McGough (2006), Orphanides and Williams (2007), Ellison and Yates (2007), Huang et al. (2009), Carceles-Poveda and Giannitsarou (2008), Eusepi and Preston (2011) and Milani (2011). In the current context constant gain is particularly natural since agents will be aware that the announced policy change will

\footnotetext{
${ }^{15}$ However, in Section 4, we consider the implications of using past changes in government spending to re-initialize the parameter estimates following the policy change. Also, if repeated policy changes take place that are qualitatively and quantitatively similar, then agents might plausibly make use of this information using procedures along the lines of Section 4 of Evans et al. (2009).

${ }^{16}$ Giving a constant weight of $\gamma$ to the most recent data point implies discounting older data as the sample size increases.
} 
induce changes in forecast-rule parameter values taking a possibly complex and time-varying form. Use of a constant-gain rule allows parameter estimates to more quickly track changes in parameter values than does straight ("decreasing-gain") least squares.

Analogously, the RLS formulas corresponding to estimates of Eqs. (19) and (20) are

$$
\begin{aligned}
& \phi_{w, t}=\phi_{w, t-1}+\gamma R_{t}^{-1} z_{t-1}\left(w_{t-1}-\phi^{\prime}{ }_{w, t-1} z_{t-1}\right), \\
& \phi_{r k, t}=\phi_{r k, t-1}+\gamma R_{t}^{-1} z_{t-1}\left(r_{k, t-1}-\phi_{r k, t-1}^{\prime} z_{t-1}\right) .
\end{aligned}
$$

with $R_{t}$ being given by (23). Note that we have set the gain to be the same in all of the regressions (this is done only for simplicity and is not essential). The initial values of all parameter estimates $\phi$ and $R$ are set to the initial steady state values under RE. See Appendix B for details.

\subsection{Surprise permanent policy change}

We first consider the benchmark case of a surprise change in government spending that takes place immediately. This is a scenario that is frequently studied in the RE literature (see e.g. Baxter and King, 1993; Aiyagari et al., 1992; Romer, 2011). ${ }^{17}$ It would, therefore, be of interest to study a surprise policy change under learning and compare with the corresponding RE dynamics. As we will see this provides interesting insights. ${ }^{18}$

Fig. 1 compares the dynamics under RE and learning for an increase in government spending that takes place in period 1 and which was not anticipated by agents. The variables plotted are capital $\left(k_{t}\right)$, gross investment $\left(i_{t}=k_{t+1}-(1-\delta) k_{t}\right)$, consumption $\left(c_{t}\right)$, labor $\left(n_{t}\right)$, output $\left(y_{t}\right)$, capital-labor ratio $\left(k_{t} / n_{t}\right)$, wages $\left(w_{t}\right)$ and the interest rate $\left(r_{t}\right)$. In all of the figures below, period $t=0$ depicts the initial steady state values of the variables. We assume the following parametric form for the figures: $\sigma=\epsilon=1, \zeta=4, \delta=0.025, \alpha=1 / 3, \beta=0.985, \rho=0.9, \bar{v}=1.359, g_{0}=0.20$, and $\gamma=0.04$ in the learning rule.

The parameter values used conform to the ones used in the real business cycle literature, see e.g. King and Rebello (1999) or Heijdra (2009). The value of $\beta$ used implies a quarterly real rate of interest of $1.5 \%$ (6\% annually); the value of $\delta$ implies an annualized rate of depreciation of $10 \%$ per annum; $\bar{v}=1.359$ is chosen to normalize output to (approximately) unity. The government spending/output ratio is $21 \%$, that of investment/output ratio is $20 \%$ and that of consumption/output ratio is $59 \%$. In our baseline case, the initial steady state values are $\bar{n}=0.22, \bar{k}=8.29, \bar{c}=0.59, \bar{w}=3.04$.

Our choice of the gain parameter $\gamma=0.04$ is in line with most of the literature, e.g. Branch and Evans (2006), Orphanides and Williams (2007) and Milani (2007). Eusepi and Preston (2011) use a much smaller value for the gain, but they do not consider changes in policy, for which a larger value of $\gamma$ is more appropriate. ${ }^{19}$

$\tilde{u}_{t}$ is assumed to be distributed uniformly with a support of $(-0.005,0.005)$. For the policy exercises, there is an increase in government spending from $g_{0}=0.20$ to $\bar{g}=0.21$ (a $5 \%$ increase) that takes place at $t=1$. We plot the mean time paths for each endogenous variable over 20,000 replications. We focus attention on the mean time path across replications since this is the most salient aspect of the differences between the RE and learning dynamics when there is a change in policy.

We first describe the dynamics under RE of the surprise increase in government expenditure. These dynamics are standard; see for instance Baxter and King (1993, pp. 321-322) and Heijdra (2009, Chapter 15). We can get some (qualitative) intuition from the saddle path dynamics considered in Heijdra (2009, Figs. 15.1 and 15.2)], in the deterministic continuous-time RBC model for such a surprise, permanent change. This is reproduced as our Fig. 7 at the end of the paper. The $C S E_{0}, C E_{0}$ lines represent the initial capital stock and consumption equilibrium lines respectively with $E_{0}$ the initial steady state. $C S E_{1}$ is the capital stock equilibrium line after the increase in government spending and the new steady state is $E_{1}$. Consumption falls immediately on impact from point $E_{0}$ to point $A$ on the new saddle path (SP $\left.P_{1}\right)$ in Fig. 7 , i.e. consumption under-shoots the new steady state $E_{1}$ on impact. Thereafter, the dynamics for consumption and capital are monotonically increasing along $S P_{1}$ to the new steady state $E_{1}$.

These RE qualitative dynamics are confirmed by the behavior of $c_{t}, k_{t}$ in Fig. 1, which also illustrates the dynamics of other important endogenous variables $n_{t}, i_{t}, y_{t}, k_{t} / n_{t}, w_{t}$, and $r_{t}$. Intuitively, the permanent increase in government spending has a large wealth effect on individuals, reducing their permanent income. Since neither consumption nor leisure are inferior goods, individuals respond by reducing consumption and leisure dramatically, so that labor supply increases. Consumption under-shoots (and labor supply over-shoots) the new steady state on impact as shown in Fig. 1. Since the capital stock is predetermined, the boost in labor input on impact increases output and the real interest rate and reduces wages. In the short run, there is a boom in investment leading to a rising path of capital. All variables then move monotonically towards the new steady state.

\footnotetext{
17 Baxter and King (1993) analyze surprise permanent and temporary changes in government spending in the neoclassical model while Ljungqvist and Sargent (2012, Chapter 11) analyze some anticipated changes in policy in deterministic neoclassical models with elastic and inelastic labor supply.

${ }^{18}$ In the notation of Section 3.1, for the surprise permanent change, the dynamics under learning has $S \tau_{h, t}^{e}=(\beta /(1-\beta))\left(\bar{g}^{\prime}-\bar{g}\right)$ for all $t \geq 1$ since the anticipatory effects are absent when the policy change takes the agents by surprise.

19 Our results are qualitatively robust to a range of values for the gain parameter; see Section 4 for a discussion. The learning rule uses a projection facility to keep the dynamics of capital bounded since the autoregressive root of the capital process in the RE equilibrium is close to one. The projection facility is set to be used outside the range $(0.01,0.99)$; however, it is not used at all with our baseline gain of 0.04 .
} 

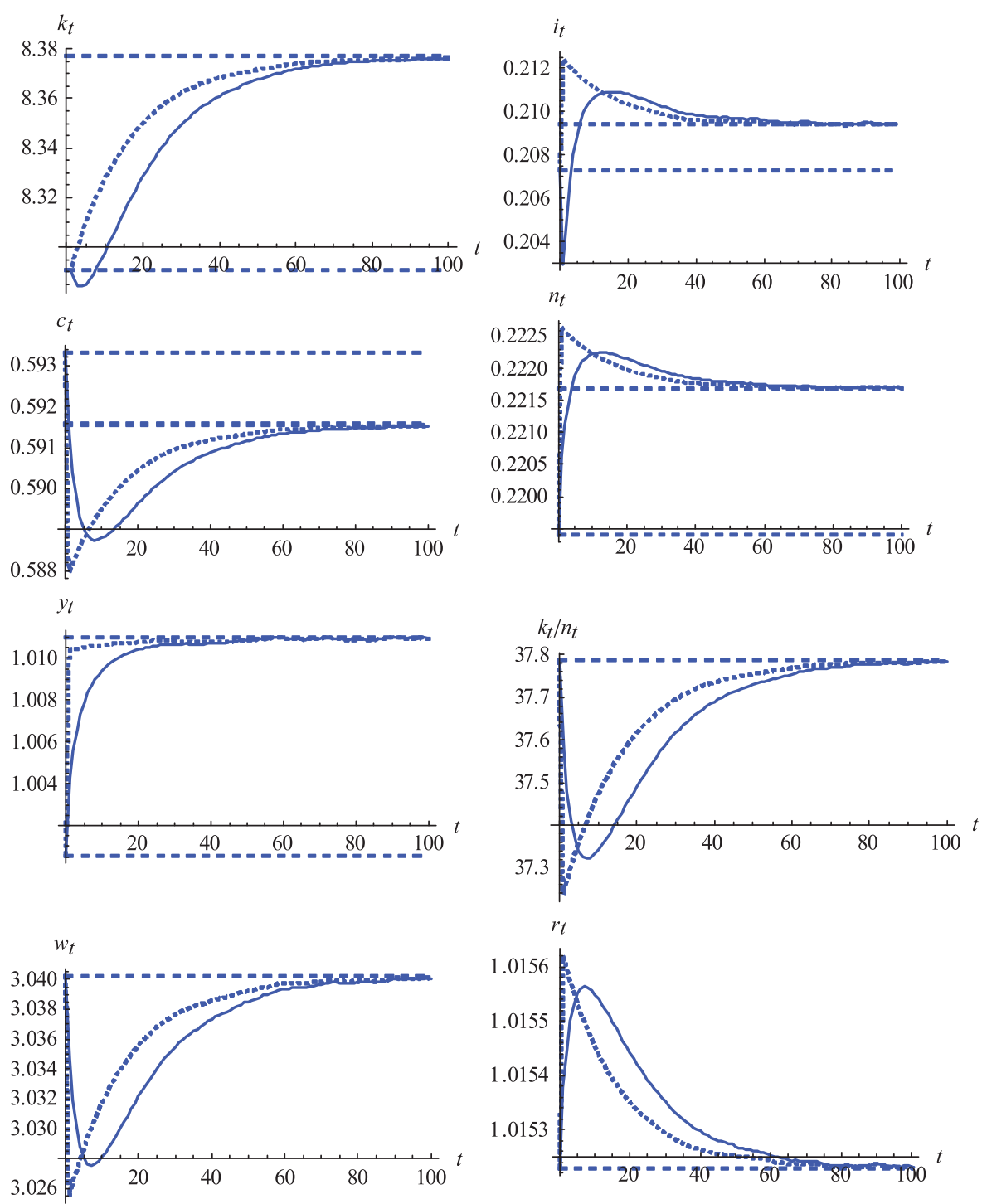

Fig. 1. Dynamic paths for a surprise permanent increase in government spending. The solid lines are the learning paths while the dashed lines are the RE paths. The horizontal dashed lines depict the old and the new steady states. Mean paths over 20,000 simulations.

Under learning, the most striking difference from RE is in the behavior of investment. Instead of the strong investment boom that characterizes the RE dynamics, in the early periods under learning we have the opposite case of a large drop in investment leading in fact to disinvestment (negative net investment $k_{t+1}-k_{t}=i_{t}-\delta k_{t}$ ) and hence a falling path of capital in the initial periods after the policy change. Why does this happen under learning? One way to view this is that at $t=1$ agents do not yet realize that the permanent increase in government spending will lead to a higher steady state capital stock; under RLS learning, agents figure this out gradually as they accumulate more data and update their parameter estimates.

More specifically, in terms of the equilibrium dynamic system under learning, the mechanism is as follows. At $t=1$, consumption falls because of the increase in $S \tau_{h, t}^{e}$. However, because wage and interest rate expectations are predetermined, the fall in consumption and the increases in employment and output are all less than under RE. Under RE the paths of lower future $w_{t}$ and higher $r_{t}$ are fully anticipated, magnifying the impact relative to the learning path in which expectations are initially unchanged. Under learning $w_{t+s}^{e}, r_{t+s}^{e}$ gradually respond to the data, leading initially to a gradual fall in $w_{t+s}^{e}$ (and rise in $r_{t+s}^{e}$ ) before eventually rising towards the steady state.

As a consequence of the smaller sizes of the impacts on output and consumption at $t=1$, the increase in $g$ necessarily leads to a lower level of $i_{t}$ under learning than under RE, and in fact we see a sharp reduction in investment. In the periods immediately following the policy change, expectations of wages and interest rates adjust. Two factors are at work. The lower capital stock in the periods soon after the policy change leads to lower forecasts of future wages and higher forecasts of future interest rates and thus lower $S w_{t}^{e}$ and higher $S r_{t}^{e}$. This leads to a further reduction in $c_{t}$, and increases in $n_{t}$ and $y_{t}$, which results in increases in $i_{t}$ from its low level at $t=1$. After several periods this process is sufficient to restore $k_{t}$ to an 
Table 1

Impact effects on key variables (in percentage terms) of a permanent policy change under rational expectations (RE) and under learning (RLS) for the surprise and announced changes.

\begin{tabular}{|c|c|c|c|c|c|c|}
\hline $\begin{array}{l}\text { Impact } \\
\text { Effects }\end{array}$ & $\begin{array}{l}\text { Surp } \\
\text { RE }\end{array}$ & $\begin{array}{l}\text { Surp } \\
\text { RLS }\end{array}$ & $\begin{array}{l}T_{p}=5 \\
\mathrm{RE}\end{array}$ & $\begin{array}{l}T_{p}=5 \\
\text { RLS }\end{array}$ & $\begin{array}{l}T_{p}=29 \\
\mathrm{RE}\end{array}$ & $\begin{array}{l}T_{p}=29 \\
\text { RLS }\end{array}$ \\
\hline$c_{t}$ & -0.90 & -0.34 & -0.66 & -0.31 & -0.10 & -0.22 \\
\hline$n_{t}$ & 1.47 & 0.55 & 1.08 & 0.51 & 0.17 & 0.36 \\
\hline$i_{t}$ & 2.49 & -2.07 & 5.38 & 2.55 & 0.86 & 1.78 \\
\hline$y_{t}$ & 0.98 & 0.37 & 0.72 & 0.34 & 0.12 & 0.24 \\
\hline$k_{t} / n_{t}$ & -1.45 & -0.55 & -1.07 & -0.51 & -0.17 & -0.36 \\
\hline$w_{t}$ & -0.49 & -0.18 & -0.36 & -0.17 & -0.06 & -0.12 \\
\hline$r_{t}$ & 0.04 & 0.015 & 0.03 & 0.014 & 0.005 & 0.009 \\
\hline
\end{tabular}

upward path, accompanied by a fall in $n_{t}$, and an increase in $k_{t} / n_{t}$ drives $w_{t}$ upwards and $r_{t}$ downwards to their steady state values. In addition, coefficient estimates under RLS learning gradually adjust in response to the shock and the evolution of the data. Eventually the coefficients converge to a distribution centered on the REE values corresponding to the new steady state.

Table 1, compares these impact effects under RE and learning. Compared to RE the paths of $c_{t}, n_{t}$ and $k_{t} / n_{t}$ under learning adjust less on impact and respond more sluggishly, leading to a hump-shaped response of $c_{t}, n_{t}$ and $i_{t}$, with $i_{t}$ eventually overshooting the new steady state (in effect this compensates for the low levels of investment in the initial periods). ${ }^{20}$ This also implies that the paths followed by $c_{t}, n_{t}$ and $k_{t} / n_{t}$ (and hence $w_{t}$ and $r_{t}$ ) in the periods following the policy change are qualitatively in opposite directions under learning compared to that under RE; e.g. $c_{t}, w_{t}$ are falling under learning initially whereas they are rising under RE.

\subsection{Anticipated permanent policy change}

We now examine the effects of an anticipated change in policy that is announced credibly in period 1 . The dynamic effects under both RE and learning depend on how far in advance the policy change is announced. We, therefore, consider two values of $T_{p}$ in what follows. Fig. 2 plots the dynamics for an anticipated, permanent increase in government spending to take place in period $t=5$, i.e. $T_{p}=5$. We interpret a period as a quarter and frequently refer to this as an announcement one year in advance. The parameter values used are the same as those for Fig. 1 (and in fact in all of the figures below). Fig. 3 illustrates the dynamics when $T_{p}=29$ (we refer to this as an announcement seven years in advance).

We first summarize the effects of the policy change under RE. We can again use Fig. 7 to help us understand the dynamics. When $T_{p}$ is small (like $T_{p}=5$ in Fig. 2), the impact effect on $c_{t}$ at $t=1$ is quite large (though smaller than that for the surprise change) and it under-shoots the new steady state $E_{1}$. The dynamics, thereafter, is governed by the phase diagram implied by the curves $C E_{0}, C S E_{0}$ since $g_{t}$ is unchanged until $T_{p}$. The phase diagram implies that $c_{t}$ and $k_{t}$ rise monotonically during the anticipatory phase until the saddle path $S P_{1}$ is hit when $T_{p}=5$ (and the dynamics are then governed by the $C E_{0}, C S E_{1}$ lines). Thereafter, the paths of $c_{t}$ and $k_{t}$ continue to increase monotonically along $S P_{1}$ until the steady state $E_{1}$ is reached.

When $T_{p}$ is large (like 29 in Fig. 3), the impact effect on $c_{t}$ at $t=1$ is much smaller and does not under-shoot the new steady state $E_{1} . c_{t}$ and $k_{t}$ rise monotonically initially until the dynamics hits the $C E_{0}$ line. Thereafter, $c_{t}$ falls but $k_{t}$ continues to rise until the new saddle path $S P_{1}$ is reached at $T_{p}=29$. The paths of $c_{t}$ and $k_{t}$ then monotonically decrease along $S P_{1}$ towards the new steady state $E_{1}$. Thus, $k_{t}$ increases monotonically until $t=29$ over-shooting the new steady state before a gradual decrease.

These effects are confirmed by the dynamics under RE shown in Figs. 2 and 3. For example, $c_{t}$ falls on impact with over-shooting of $c_{t}$ observed on impact in Fig. 2 but not in Fig. 3. $k_{t}$ over-shoots the new steady state under RE when $T_{p}=29$ (see Fig. 3) but not when $T_{p}=5$ (see Fig. 2).

Under learning, only the announced increase in future taxes reduces $c_{t}$ at $t=1$, by Eq. (8), since expectations of wages and interest rates are pre-determined. The impact effects under learning (like that under RE) are reduced as $T_{p}$ increases. However, compared to RE, the impact effects are smaller under learning when $T_{p}$ is small (see Fig. 2) while they are larger when $T_{p}$ is large (see Fig. 3). Table 1 summarizes the impact effects in percentage terms for the surprise and the announced permanent changes illustrated in Figs. 1-3.

We consider the dynamics under learning in more detail for the case $T_{p}=29 .^{21}$ The initial fall in consumption, due to the higher anticipated future taxes $S \tau_{h, t}^{e}$, leads to a temporary investment boom and a period of capital accumulation. However, under learning this is soon followed by a considerable period in advance of $T_{p}=29$, specifically $t=4, \ldots, 23$, in which there are higher wages and expected wages, $S w_{t}^{e}$, and lower interest rates and expected interest rates, $\mathrm{Sr}_{t}^{e}$ than under $\mathrm{RE}$. These

\footnotetext{
${ }^{20}$ In RBC models with learning, hump-shaped responses to productivity shocks have been observed by Eusepi and Preston (2011), Branch and McGough (2011), and Huang et al. (2009). The latter also emphasize the plausible labor market dynamics that arise from the learning model. However, none of these papers focus on changes in government spending.

${ }^{21}$ For $T_{p}=5$ the qualitative dynamics are similar under learning, except that the overshooting of $c_{t}$, $w_{t}$, and $r_{t}$ is not observed in the preimplementation period.
} 

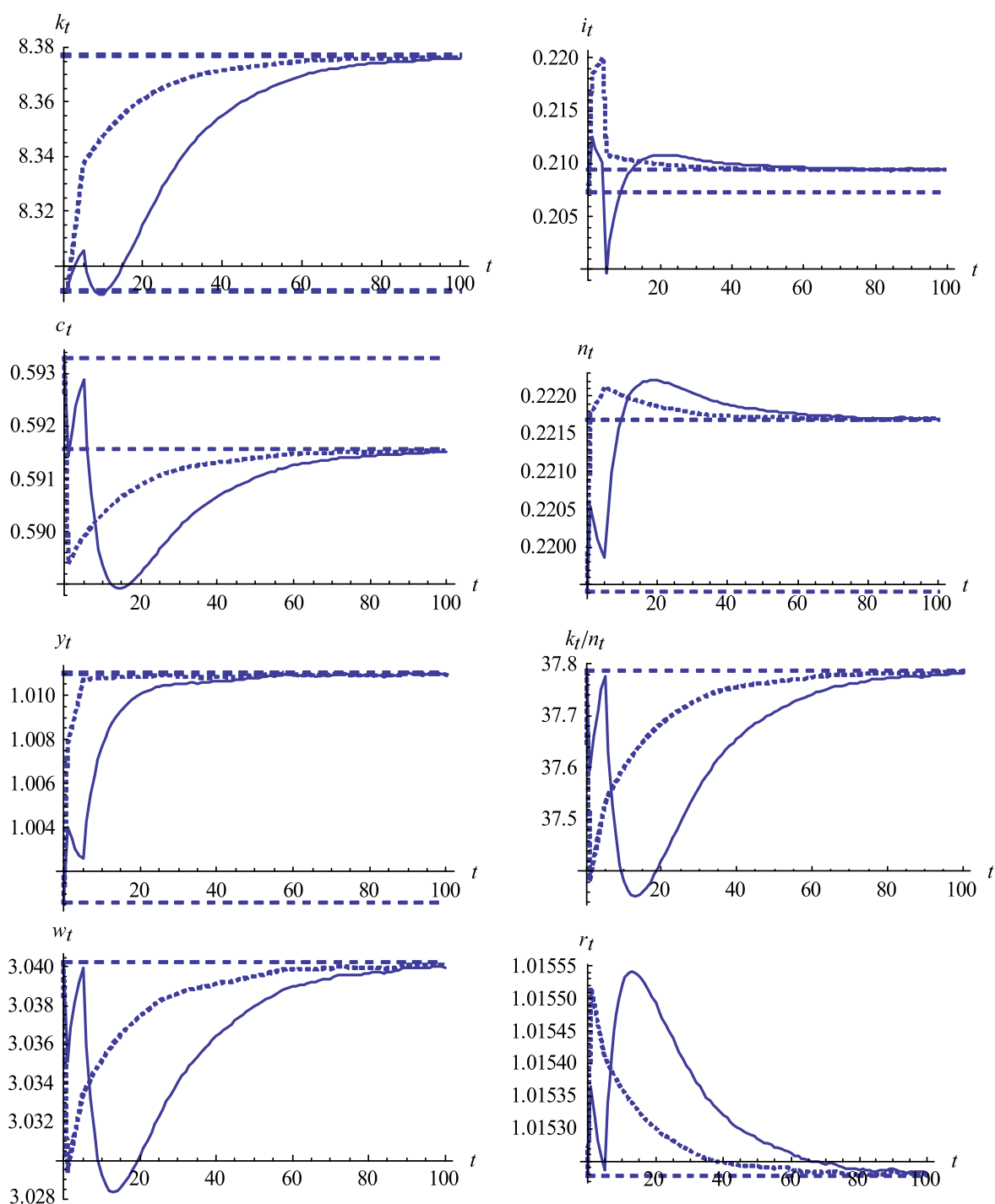

Fig. 2. Dynamic paths for an anticipated permanent increase in government spending taking place in period 5. The solid lines are the learning paths while the dashed lines are the RE paths. The horizontal dashed lines depict the old and new steady states. Mean paths over 20,000 simulations.

expectations under learning are partially self-fulfilling, in that they are accompanied by higher $c_{t}$, lower $n_{t}$ and higher $k_{t} / n_{t}$, compared to the RE path. As a result, the qualitative dynamics of $n_{t}$ and $y_{t}$ under learning are actually opposite to that under RE throughout most of the pre-implementation phase, in the sense that $n_{t}$ and $y_{t}$ are falling over time under learning whereas they rise over time fairly dramatically under RE.

Continuing with the learning scenario, the optimistic assumptions of high future wages and low future interest rates offset the higher expected taxes $S \tau_{h, t}^{e}$, and consequently when $T_{p}=29$ arrives, employment is back to initial levels and consumption is actually slightly larger than it was initially. During period $T_{p}=29$ when the government spending increases, there is virtually no impact on $c_{t}$ or $n_{t}$, or on $w_{t}, r_{t}$, since the tax increases had been fully anticipated. Consequently almost the full impact of the increase in $\bar{g}$ at $T_{p}$ is on $i_{t}$ and thus on $k_{t+1}$. This corresponds to a similar decrease in $i_{t}$ in the RE case. However, in the learning case the fall in the capital stock after $T_{p}=29$, during periods $t=30-35$, leads to a sharp reduction in wages and a sharp increase in interest rates that were not correctly anticipated by agents. There is then a sustained period for $t>T_{p}$ of low $c_{t}$, low $w_{t}$, high $r_{t}$ and high $n_{t}$, (with both $n_{t}$ and $i_{t}$ overshooting their new higher steady state levels), as agents adjust their expectations to the post-policy implementation reality, with eventual convergence to the new steady state.

To summarize, only the direct wealth effects from the anticipated change in government spending (and taxes) are fully foreseen under learning in the anticipatory phase. Under learning, in contrast to RE, agents do not correctly foresee the path of future wages and interest rates. This leads to overoptimism concerning wages and interest rates in the pre-implementation period, and a substantial correction following implementation, with a period of low wages, low consumption and high interest rates. 

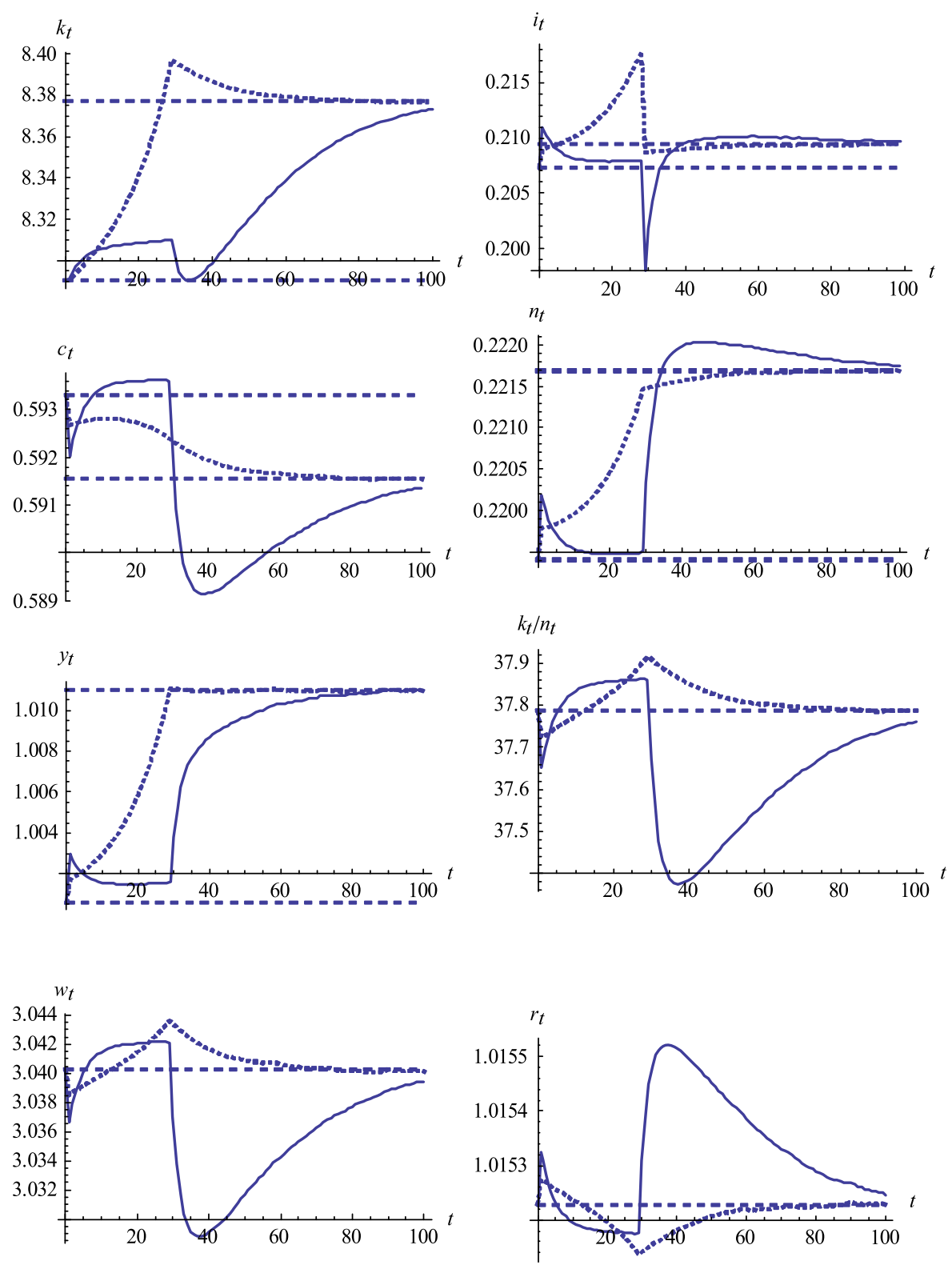

Fig. 3. Dynamic paths for an anticipated permanent increase in government spending taking place in period 29. The solid lines are the learning paths while the dashed lines are the RE paths. The horizontal dashed lines depict the old and new steady states. Mean paths over 20,000 simulations.

\subsection{Interpretation of results}

For both surprise and anticipated permanent increases in $g$ we see the following main qualitative features:

1. There are large impact effects for both the RE and learning solutions, and these effects get smaller as $T_{p}$ increases. The impact effects under learning are smaller than under RE for surprise changes but the opposite is true when $T_{p}$ is large.

2. The dynamics of variables under RE and learning can be in qualitatively opposite directions for some periods after the impact effects. For the surprise change, $k_{t}, c_{t}$ are falling after the policy change under learning while they are rising under $\mathrm{RE}$ ( $n_{t}$ is rising under learning and falling under RE during this time). These features lead to a hump-shaped response in variables under learning that is absent under RE. Similarly, for the announced change, $i_{t}, n_{t}$, and $y_{t}$ are all falling under learning in the pre-implementation phase whereas they are all rising under RE in this time period.

3. For anticipated future permanent changes in $g$, under learning there is essentially no impact on $c$ or $n$ on the date when the policy is implemented, and in this respect is like RE. The reasons are the same: the tax change is fully anticipated and agents aim to smooth their consumption path. 
4. There can be classic "overshooting" results for both learning and RE paths. For example, in the case of an announced increase in $g$ when $T_{p}$ is large, the path for $k_{t}$ rises above the new higher steady state before eventually converging to it under RE. However, overshooting is a far more prominent feature of learning paths; for an announced change in $g$, consumption falls instantaneously before gradually rising until $T_{p}$; there is then a substantial fall in $c$ under-shooting the new steady state before converging to it.

5. Related to this last point, the learning paths exhibit oscillatory convergence that is particularly pronounced for announced policy changes. For example, in the announced case, under learning, $k_{t}$, after its initial rise, falls for a period before increasing and eventually converging. Other variables like $c_{t}, n_{t}, y_{t}, k_{t} / n_{t}$ (hence, $w_{t}$ and $r_{t}$ ) all exhibit oscillatory convergence as well.

We now discuss the intuition for the results under learning. The key feature is that the effects from the change in expected future government spending and taxes are felt immediately (since agents foresee the path of $g_{t}$ even under learning), while the implications for expected future wages and interest rates evolve gradually in response to the data.

Consider the effect of an anticipated permanent increase in $g$ illustrated in Figs. 2 and 3. On announcement of the future increase in $g$, agents immediately understand the implications for their wealth of their future higher taxes and they adjust their consumption and labor supply accordingly. During the period $t<T_{p}$ they also revise their expectations of future wages and interest rates in response to the data. What they do not foresee, however, is that when the policy is implemented this will lead to a crowding out of capital that will in turn eventually reduce wages and increase interest rates. Consequently, for $t>T_{p}$ there is another period of adjustment as agents learn the properties of the new equilibrium steady state.

How reasonable is our implicit assumption that agents will not foresee the extent to which capital is crowded out by $g$ in the period following implementation? We think this is very plausible. For agents to deduce that there will be the decline in the capital stock following $T_{p}$ they would need not only to understand the capital accumulation equation (12), but also to accurately forecast aggregate consumption $c_{t}$ and aggregate labor supply $n_{t}$ during the period following $T_{p}$. As we have already indicated in our earlier discussion of RE, this in turn requires an implausibly high degree of structural knowledge of the economy, as well as a belief that this structural information is common knowledge, that all agents are fully rational and capable of computing equilibrium paths, and that this is common knowledge. ${ }^{22}$ These are precisely the assumptions that the adaptive learning literature aims to avoid.

The approach taken in this paper is to examine the implications of assuming that agents have some structural information pertinent to their decision problem, here the path of future taxes, but that they use econometric forecasting procedures for other key variables. An implication of our approach is that agents are likely to make systematic mistakes when confronted with announced future increases in government spending: while the tax implications will be understood, agents may become overoptimistic in advance of the policy implementation, leading to a subsequent correction.

\subsection{Oscillatory dynamics under learning}

We have noted that oscillatory dynamics is a prominent feature under learning. The system under learning combines two types of dynamics. First consider the case of the permanent surprise increase in $g$. Under RE the policy change in effect reinitializes the system so that the "initial" capital stock is below its new steady state values. Under RE the system dynamics are inherently monotonic, along the new saddle path, since the state is given by (16) and (17), which implies that the path of capital follows:

$$
k_{t+1}=\bar{b}_{k}+\bar{a}_{k k} k_{t}+\bar{a}_{k v} \hat{v}_{t},
$$

where $\bar{b}_{k}, \bar{a}_{k k}=\lambda_{2}^{\prime}$ and $\bar{a}_{k v}$ denote new steady-state values.

Under learning the system dynamics are driven by the values of the forecast parameters as well as by the current state variables. The forecast functions (18)-(20) are characterized by a vector of estimated coefficients $\theta=\left(b_{k}, a_{k k}, a_{k v}, b_{w}, a_{w k}\right.$, $a_{w v}, b_{r}, a_{r k}, a_{r v}$ ), which are updated over time using RLS. If, at the time of the policy change, the coefficient values for $\theta$ changed immediately to the new RE values $\bar{b}_{k}, \bar{a}_{k k}, \bar{a}_{k v}$, and the other coefficients changed analogously, then our temporary equilibrium system would replicate the REE.

Under adaptive learning, however, the coefficients gradually evolve towards the new RE values in response to data and the RLS updating scheme. One can show the actual law of motion (ALM) dynamics for given parameters $\theta$ takes the same form as the PLM but with parameters $T(\theta)$ instead of $\theta$. The mapping $T: \mathbb{R}^{9} \rightarrow \mathbb{R}^{9}$ can be computed numerically and REE parameter values are a fixed point $\bar{\theta}=T(\bar{\theta})$. Under learning the parameters $\theta(t)$ evolve over time. Denoting $\theta^{*}(t)=T(\theta(t))$ and using $b_{k}^{*}(t)$, etc., for the components of $\theta^{*}$, the (linearized) dynamics under learning are given by

$$
\begin{aligned}
& k_{t+1}=b_{k}^{*}(t)+a_{k k}^{*}(t) k_{t}+a_{k v}^{*}(t) \hat{v}_{t}, \\
& w_{t}=b_{w}^{*}(t)+a_{w k}^{*}(t) k_{t}+a_{w v}^{*}(t) \hat{v}_{t}, \\
& r_{k, t}=b_{r}^{*}(t)+a_{r k}^{*}(t) k_{t}+a_{r v}^{*}(t) \hat{v}_{t} .
\end{aligned}
$$

\footnotetext{
22 The strong assumptions required for agents to be able to deduce, and hence coordinate on RE, are discussed in Guesnerie (2002).
} 
Thus under learning the system combines the linear state dynamics corresponding to this system with parameters $\theta^{*}(t)$ (equal to $\bar{\theta}$ at an REE) and the RLS dynamics governing the evolution of $\theta(t)$ over time. The resulting system for the endogenous variables is a nonlinear stochastic dynamic system that can include oscillatory responses to structural change.

For a surprise permanent increase in $g$, the hump-shaped response for $k_{t}, i_{t}, c_{t}$ and $n_{t}$ results from this combined dynamics. Immediately after the policy shock, PLM parameters are at the old steady state values $\bar{\theta}$. This leads to smaller impact effects than under RE and a decline in $k_{t}$. This leads to further movements of variables away from the new steady state as discussed above. However, over time $\theta(t)$ evolves towards the new REE values $\bar{\theta}^{\prime}$, leading to the eventual monotonic convergence seen in Fig. $1 .{ }^{23}$ For anticipated permanent increases in $g$, implementation in $T_{p}$ leads to a second period of oscillatory dynamics before convergence to the final steady state.

The importance of cyclical or oscillatory dynamics has been emphasized in RE models by, e.g. Farmer (1999, Chapter 7), Farmer and Guo (1994) and Azariadis et al. (2004). These papers also argue that such dynamics are a feature of US data. Farmer and Guo (1994) obtain cyclical dynamics in RBC-type models with nonconvexities (see also Baxter and King, 1991). In Azariadis et al. (2004) the oscillatory dynamics arise from the overlapping generations structure. Our results indicate that with adaptive learning, oscillatory dynamics can be expected to arise in response to fiscal policy or other structural changes in standard RBC models. It would be interesting to examine this feature of adaptive learning in more detail and to compare its implications with the data. ${ }^{24}$

\section{Further results}

In this section we consider two additional points. The first, which is more straightforward, is that we consider the impact of the size of the learning gain parameter on our results. The second, which is methodologically more fundamental, is to consider the possibility that agents use past variations in government spending to estimate the impact of the permanent policy change on future wages and interest rates.

\subsection{Effect of gain parameter}

As earlier discussed the use of constant gain learning is particularly appropriate when there is structural change like the policy change considered in this paper. It is clearly of interest to know the effect of the size of the gain parameter on the dynamics. We restrict attention to the permanent surprise increase in government spending considered in Fig. 1. Fig. 4 shows the dynamics of $i_{t}, c_{t}, n_{t}$ and $y_{t}$ for two alternative values of the gain parameter: $\gamma=0.01$ on the left and $\gamma=0.08$ on the right. As can be seen the qualitative dynamics are essentially the same as in Fig. 1. For example, for each choice of the gain $c_{t}$ falls less on impact compared to RE and follows a hump-shaped path that eventually falls below the RE path before converging asymptotically to the new steady state. ${ }^{25}$

The main impact of the gain is that a smaller gain stretches out the time frame of the paths under learning. For example, the minimum of the consumption path occurs in period 6 when $\gamma=0.08$, in period 8 when $\gamma=0.04$ and in period 16 when $\gamma=0.01{ }^{26}$ For the same reason, convergence to the new steady state is slower under learning when gains are smaller. As noted in Section 3.5 the variable paths under learning combine two types of dynamics. The underlying reason for the timestretching effect of small gains is slower adjustment of the forecast parameters under learning, an effect which is wellknown in the learning literature.

Our benchmark choice of $\gamma=0.04$ is consistent with the empirical literature of adaptive learning. An alternative approach would be to calibrate its value based on the choice that minimizes a criterion like forecast squared error, along the lines of Evans and Honkapohja (2001, Chapter 14.3.4) or Marcet and Nicolini (2003). This is beyond the scope of the current paper.

\subsection{Effect of prior on policy impact}

In this section we extend the model to allow for the possibility that agents use past information concerning the impact of government spending to form a prior estimate of the impact of the policy change. Specifically, we allow for temporary fluctuations in government spending, which are included in agents' forecasting models. We then suppose that agents use these past variations in government spending to estimate the impact of the permanent policy change on future wages and interest rates.

Thus suppose that in addition to the steady state level of government spending $\bar{g}$, there are temporary government spending shocks $\hat{g}_{t}$ that follow a stationary AR(1) process. We assume that before the policy change agents have estimated

\footnotetext{
${ }^{23}$ The mean dynamics of the parameter estimates are governed by the "E-stability" differential equation $\dot{\theta}=T(\theta)-\theta$. Local asymptotic stability of an $\operatorname{REE} \bar{\theta}$ is determined by the Jabobian matrix $D T(\bar{\theta})$. Numerically for our baseline parametrization, the nonzero eigenvalues are $-4.50,-0.95,-0.64$. Since all the eigenvalues are less than one, the equilibrium is E-stable and therefore stable under least squares learning.

${ }^{24}$ See Eusepi and Preston (2011) and Milani (2011) for empirically oriented studies in models with unchanged policy.

${ }^{25}$ Another natural possibility would be for agents to reduce the size of the gain over time as the date of the policy change recedes into the past. Our qualitative results are robust to such variations in the gain sequence.

${ }^{26}$ As mentioned in Section 3.2, large gains lead to a more frequent use of the projection facility. Here for $\gamma=0.08$ the projection facility is used $1.3 \%$ of the times, whereas it is not used at all when $\gamma=0.01$ or $\gamma=0.04$.
} 

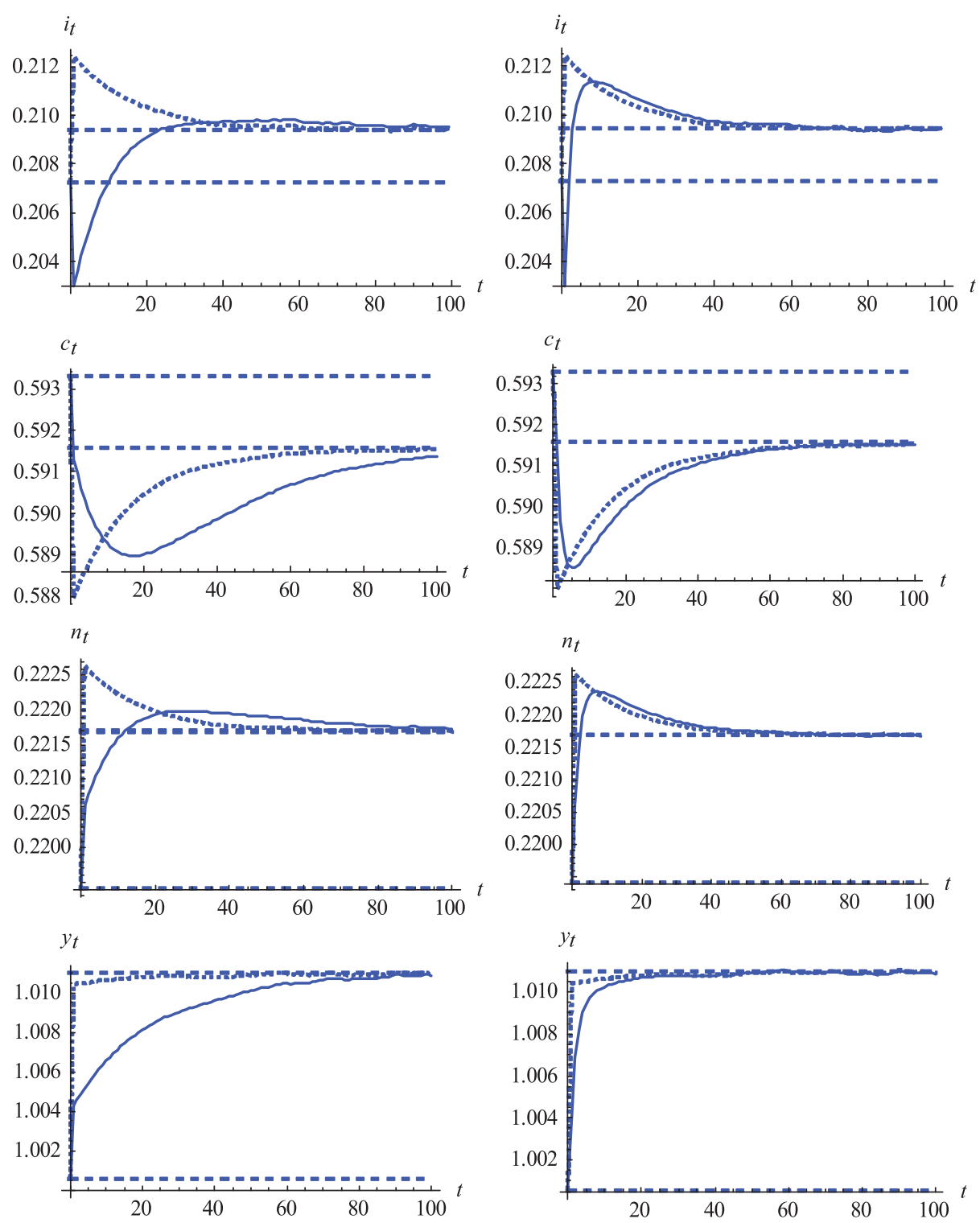

Fig. 4. Impact of gain parameter. The left hand side illustrates the dynamics with a smaller gain of 0.01 and the right hand side the dynamics with a larger gain of 0.08. Solid lines show learning dynamics and dashed line the RE dynamics. Mean paths over 20,000 replications.

the law of motion for $k_{t}, w_{t}$ and $r_{k, t}$, obtaining an estimate of the PLM with coefficients close to their RE values. We restrict attention to the case of an unanticipated permanent increase in $\bar{g}$. Because there now is assumed to have been historical variation of $g_{t}=\bar{g}+\hat{g}_{t}$, agents have estimates of the impact of $\hat{g}_{t}$ on $k_{t}, w_{t}$ and $r_{k, t}$. Earlier we argued against the use of this information by agents on the grounds that the policy change would be sufficiently different from past experience to make earlier fluctuations in $g_{t}$ of limited information value. However, it is possible that agents do use the past effects of $\hat{g}_{t}$ in forecasting the effects of the new policy.

To model this we assume now that agents have the following PLM, in which $\hat{g}_{t}$ is included as an additional state variable

$$
\begin{aligned}
& k_{t+1}=b_{k}+a_{k k} k_{t}+a_{k v} \hat{v}_{t}+a_{k g} \hat{g}_{t}+a_{k d} D \bar{g}_{t}+\text { noise, } \\
& w_{t}=b_{w}+a_{w k} k_{t}+a_{w v} \hat{v}_{t}+a_{w g} \hat{g}_{t}+a_{w d} D \bar{g}_{t}+\text { noise, } \\
& r_{k, t}=b_{r}+a_{r k} k_{t}+a_{r v} \hat{v}_{t}+a_{r g} \hat{g}_{t}+a_{r d} D \bar{g}_{t}+\text { noise, }
\end{aligned}
$$




$$
\hat{v}_{t}=\rho \hat{v}_{t-1}+\tilde{u}_{t} \quad \text { and } \quad \hat{g}_{t}=\mu \hat{g}_{t-1}+\varepsilon_{t} \quad \text { where } 0<\rho, \mu<1 .
$$

The variable $D \bar{g}_{t}$ is a discrete variable taking the value $D \bar{g}_{t}=\bar{g}^{\prime}-\bar{g}$ for all $t \geq 1$ in the policy surprise case.

We assume that coming into $t=1$ agents' estimates of the PLM have converged to the RE values corresponding to the stationary environment in which $g_{t}=\bar{g}+\hat{g}_{t}$. However, in forecasting future $k_{t+j}, w_{t+j}$ and $r_{k, t+j}$ we now allow for agents to explicitly estimate and update over time, the impact of the increased permanent level of $\bar{g}$ using $D \bar{g}_{t}$ in their PLM. A key question is the initial values $a_{k d}, a_{w d}, a_{r d}$ assigned by agents at $t=1$ when the surprise policy takes place. ${ }^{27}$ One possibility is that they treat the coefficients $\left(\bar{a}_{k g}, \bar{a}_{w g}, \bar{a}_{r g}\right)$ on $\hat{g}_{t}$, which reflect the observed impact of temporary changes, as suitable initial estimates of the impact of the permanent policy. More generally and plausibly agents would understand that the impacts of temporary changes in $g$ will be different from those of permanent changes, and use

$$
a_{k d}=(1-\omega) \bar{a}_{k g}, \quad a_{w d}=(1-\omega) \bar{a}_{w g} \quad \text { and } \quad a_{r d}=(1-\omega) \bar{a}_{r g}
$$

for a shrinkage parameter $0 \leq \omega \leq 1$. This can be viewed as reflecting a prior belief for coefficients of $D \bar{g}_{t}$ being centered at zero. $^{28}$ Put differently, $\omega$ measures the distrust agents place on the relevance of $\left(\bar{a}_{k g}, \bar{a}_{w g}, \bar{a}_{r g}\right)$ for the policy change.

In contrast to Section 3, the inclusion of the dummy variable $D \bar{g}_{t}$, with initial nonzero parameter estimates, implies that agents now immediately project policy impacts on future wages and interest rates as well as on taxes. However, these initial estimates are based on the experience of temporary changes $\hat{g}_{t}$, which as we have emphasized may provide poor guidance.

Figs. 5 and 6 show the results for a surprise permanent increase, when $\rho=0.95, \mu=0.7$ and $\omega=0.99$ or $\omega=0.5$. $^{29}$ The results for $\omega=0.99$ in Fig. 5 are quite close to those shown earlier in Fig. 1 . This is not surprising given that $\omega=1$ corresponds closely to the framework used in the main body of the paper, in which initially forecasts were based on a PLM initialized at the RE of the initial steady state, with parameters gradually adjusted over time at a rate controlled by the gain. ${ }^{30}$

For $\omega=0.5$ in Fig. 6 , the results are very different, with sharp increases in investment, employment and output (and a reduction in consumption) at the time of the policy change. These impacts now substantially exceed the response under RE. These contrasting results stem from the initial values of $\left(a_{k d}, a_{w d}, a_{r d}\right)$ based on $\bar{a}_{k g}=-0.68, \bar{a}_{w g}=-0.31$ and $\bar{a}_{r g}=0.0082$.

While these estimates do immediately capture the negative effect of higher $\bar{g}$ on future wages, they exaggerate the impact, and this is further exacerbated through $a_{k d}<0$ by an estimated lower long-run level of the capital stock. These estimates are mistaken, because the temporary effects of increases in $g_{t}$ are very different from the impact of permanent effects. In the basic RBC set-up, temporary increases in $g_{t}$ under RE have a negative effect on capital while permanent increases have a positive effect on $k_{t}$.

In summary, the pattern of under-reaction on impact, relative to RE, seen in Figs. 1 and 5, is replaced in Fig. 6 by over-reaction on impact. For $\omega$ near one, agents initially do not anticipate the general equilibrium effects on wages, leading to under-reaction. For small $\omega$, agents assume the general equilibrium effects are like those from temporary government spending shocks, leading instead to over-reaction. Eventually, of course, there is convergence to the new steady state in both cases.

These results illustrate the sensitivity of the response of the economy to the methods by which agents forecast the general equilibrium effects of the policy change. The priors used to forecast future wages and interest rates modulate the impact on $c_{t}$ and $n_{t}$ of the increase in future taxes.

\section{Further discussion and literature review}

We have employed a framework in which information about changes in the future path of fiscal policy change is incorporated into the adaptive learning approach to expectation formation. This approach has been informed by an established literature on policy change in models with rational expectations.

We discussed classic references in the Introduction. In recent work, Ramey (2011) identifies news about future fiscal policy changes and finds that whether or not government spending changes are anticipated has important implications for reconciling different empirical findings about consumption and real wages. Ramey (2009) uses an RBC framework like ours to illustrate theoretically the impact of news about future fiscal policy on the paths of aggregate variables. Our paper also assumes knowledge of the path of future government spending, but we replace the assumption of rational expectations about future wages and interest rates with forecasts based on adaptive learning. Our approach has quite different implications for impulse response functions, which could be tested in future econometric work. ${ }^{31}$

Similarly, Leeper et al. (2012) study the roles of the horizon and intensity of confidence, of fiscal news, within a calibrated New Keynesian model. They show, for example, that "no-foresight fiscal multipliers are substantially different from multipliers when there is substantial foresight." While they emphasize the importance of correctly modeling the news process within a rational expectations DSGE framework, we show that it is equally important to model correctly the expectations process of agents in

\footnotetext{
27 The RLS moment matrix estimate $R_{t}$ is now $5 \times 5$ and must also be initialized. For the $4 \times 4$ submatrix corresponding to the second-moment matrix of $\left(1, k_{t}, \hat{v}_{t}, \hat{g}_{t}\right)$ we use the RE value. To this we append $R(i, 5)=R(5, i)=0$ for $i=1,2,3,4$ and $R(5,5)=\left(\bar{g}{ }^{\prime}-\bar{g}\right)^{2}$. This implies that in the first period $a_{k d}, a_{w d}$, and $a_{r d}$ are simply adjusted by the forecast error times the gain.

${ }^{28}$ This is particularly natural in the current case since the sign of the theoretical impact on capital of a permanent increase in $\bar{g}$ can be positive, zero or negative, depending on the specific macroeconomic model employed.

${ }^{29} \mu=0.7$ is the median value used in Leeper et al. (2011). We set the standard deviation of $\varepsilon_{t}$ at 0.003 , slightly less than that of the productivity innovation.

${ }^{30}$ This allowed the intercept to adjust over time. Here the same role is played by adjustment over time in the coefficient on $D \bar{g}_{t}$.

31 Leeper et al. (2008) discuss the difficulties in estimating the true impulse response functions when agents have foresight.
} 

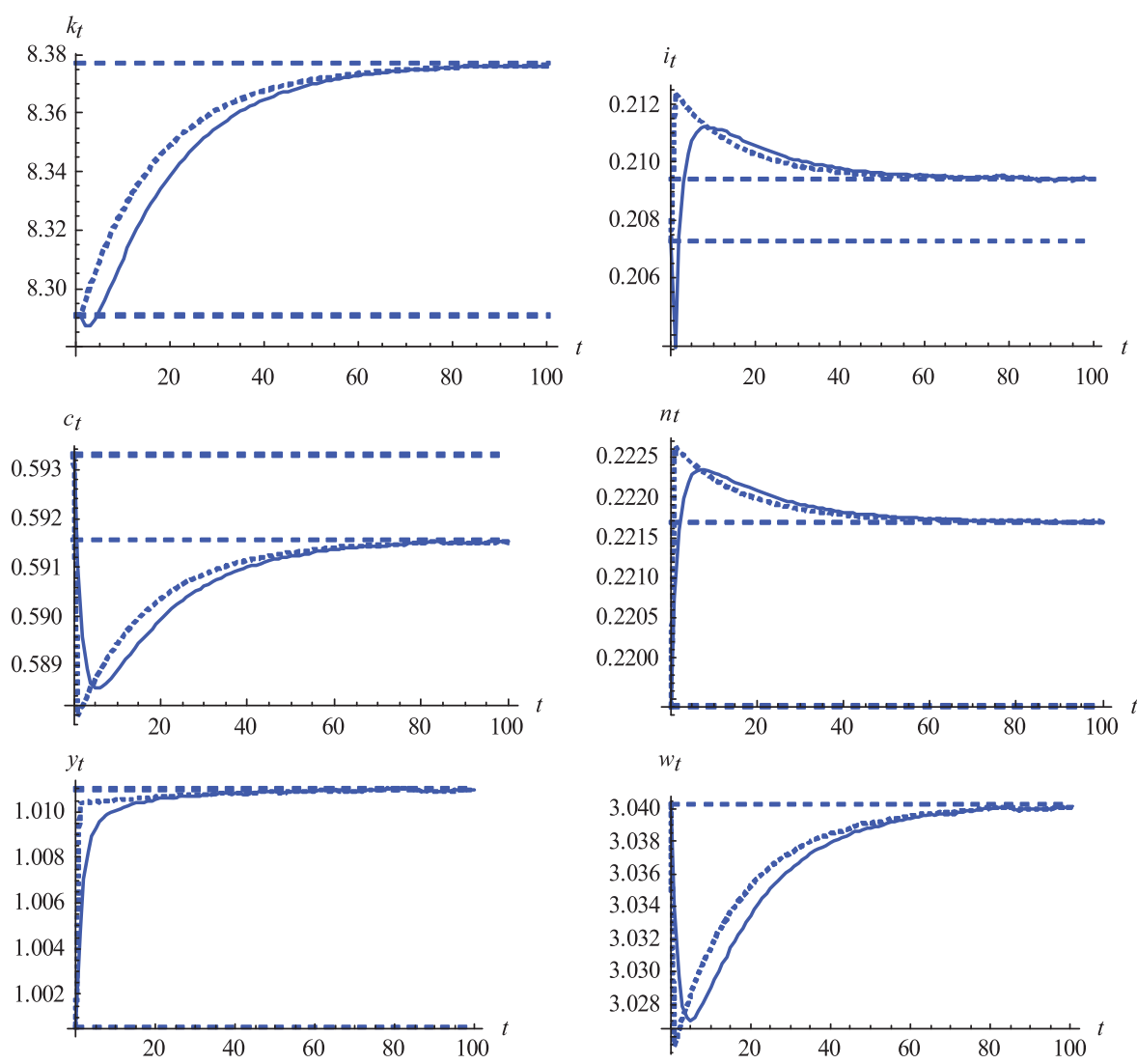

Fig. 5. Dynamic paths for a surprise permanent increase in government spending with the dummy variable included in agents's regression and $\omega=0.99$. Solid lines are the learning paths while dashed lines are the RE paths. Mean paths over 20,000 simulations.

forecasting the general equilibrium effects of policy changes. In related work of Mitra et al. (2012) we use our analysis to demonstrate the implications of our approach for salient policy issues like government spending multipliers.

In this paper we have used the basic RBC model with lump-sum taxes, balanced budgets, and no frictions. We use this stylized model in order to make as transparent as possible the importance of the lack of knowledge of the general equilibrium effects of policy changes. Clearly our approach can be extended to allow for various frictions and distortions, which would be desirable in subsequent theoretical extensions and particularly relevant for empirical work. We think it is important that empirical work on the impact of fiscal policy changes allow for the nonlinear dynamics, induced by adaptive learning, that are identified in this paper.

Other recent work, e.g. House and Shapiro (2006), Mertens and Ravn (2011), Yang (2005) and Strulik and Trimborn (2010) look at anticipated changes in distortionary labor and capital taxes in RBC-type models, and some of the news shocks papers, e.g. Beaudry and Portier (2007) and Schmitt-Grohe and Uribe (2012), consider fiscal policy news shocks. These papers emphasize partial knowledge about future policy changes like our work, but they employ the standard RE assumption. Our approach can be developed further as a complement to these results.

\section{Conclusion}

Changes in fiscal policy, in an RBC model with adaptive learning, generate mean trajectories that have both common features and significant differences from the mean paths under RE. These dynamics were examined for surprise and announced permanent fiscal changes. For announced policy changes scheduled to take place in the future, immediate anticipation effects under learning arise from the wealth effects of anticipated future tax changes, followed by additional more gradual impacts arising from changes in expected future wages and interest rates. ${ }^{32}$

The differences in dynamics under RE and adaptive learning therefore arise due to the future path of wages and interest rates being fully foreseen by RE agents, while agents learn only gradually about these variables under incomplete

\footnotetext{
${ }^{32}$ We remark that our focus on anticipated future fiscal changes is reminiscent of the literature on news shocks about future productivity changes, see Jaimovich and Rebelo (2009). The approach used in the current paper could naturally be extended to news shocks within their framework.
} 

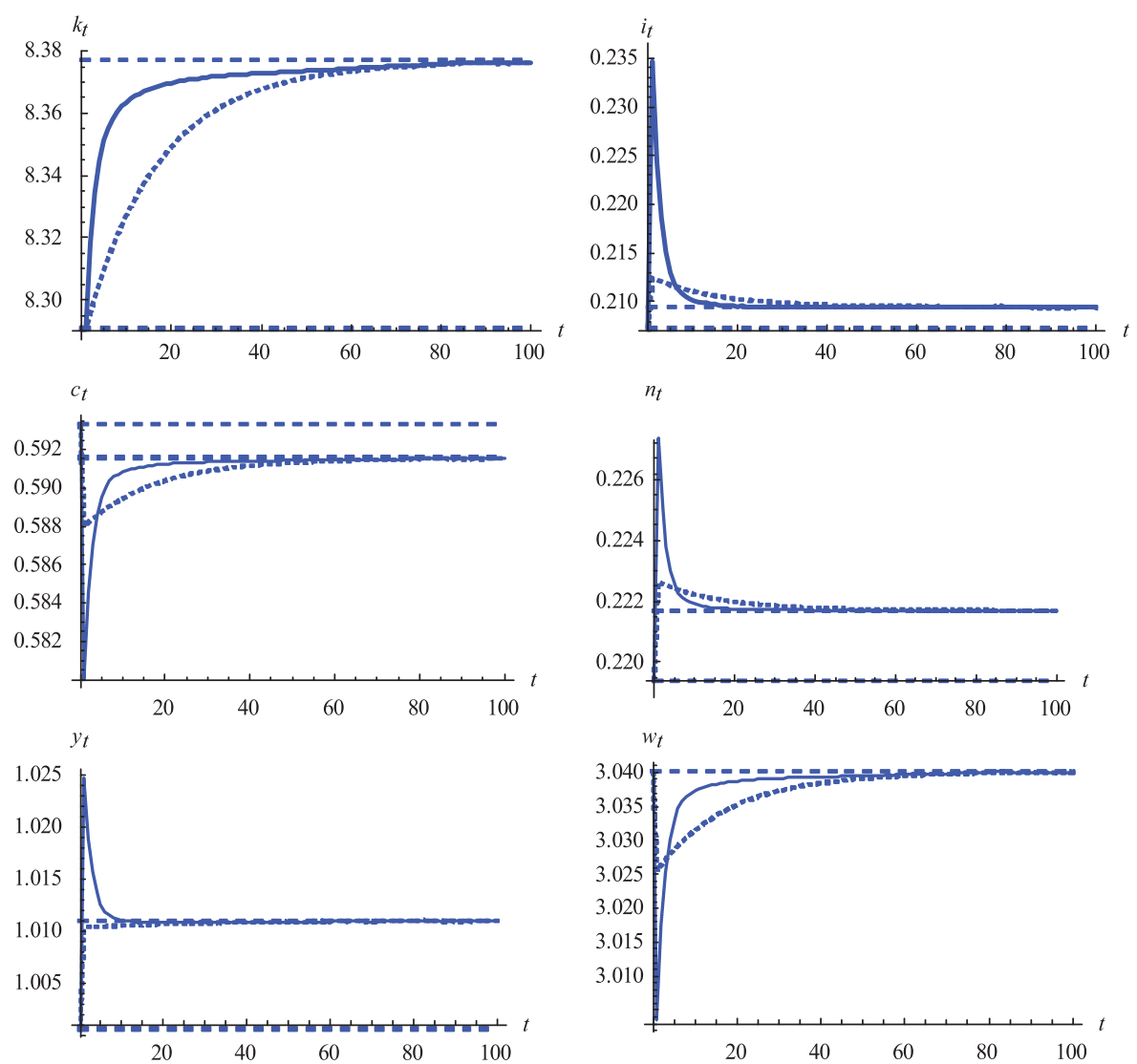

Fig. 6. Dynamic paths for a surprise permanent increase in government spending with the dummy variable included in agents's regression and $\omega=0.5$. Solid lines are the learning paths while the dashed lines are the RE paths. Mean paths over 20,000 simulations.

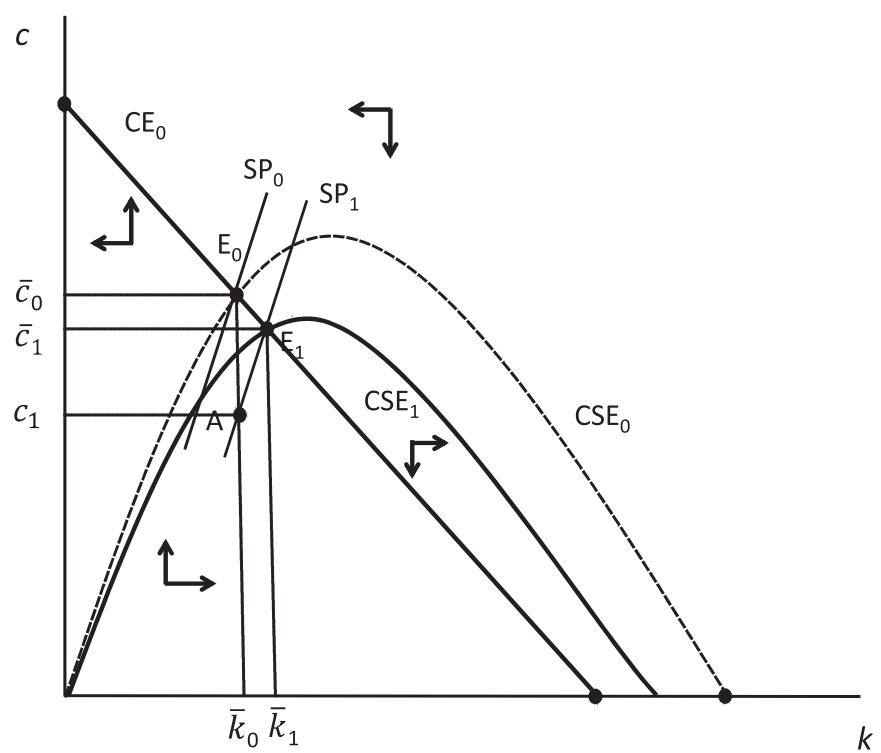

Fig. 7. Effects under RE of fiscal policy in deterministic RBC model; based on Heijdra (2009, Figs. 15.1-15.2.)

knowledge. In effect, under learning agents understand the direct wealth effects of future changes of government spending and taxes, but fail to fully anticipate the effect on factor prices of the crowding out or crowding in of changes in government spending. 
Depending on the form of the announced policy change, the size of the impact effects under learning can be either greater or smaller than under RE. In some cases the qualitative dynamics of variables can be in diametrically opposite directions under RE and learning. In addition, oscillatory dynamics emerge prominently as agents learn about the full impact of the policy change and its effect on the new steady state.

\section{Acknowledgments}

We are grateful to the associate editor and two referees for helpful comments. Financial support from Economic and Social Research Council (ESRC) Grant RES-062-23-2617 and from National Science Foundation Grant no. SES-1025011 is gratefully acknowledged. Any views expressed are those of the authors and do not necessarily reflect the views of the Bank of Finland.

\section{Appendix A. Linearizations}

The linearized wage rate, rental rate, and real interest rate equations are

$$
\begin{aligned}
& w_{t}-\bar{w}=\bar{w}\left[\left(\frac{v_{t}}{\bar{v}}-1\right)+\alpha\left(\frac{k_{t}}{\bar{k}}-1\right)-\alpha\left(\frac{n_{t}}{\bar{n}}-1\right)\right], \\
& r_{k, t}-\bar{r}_{k}=\bar{r}_{k}\left[\left(\frac{v_{t}}{\bar{v}}-1\right)-(1-\alpha)\left(\frac{k_{t}}{\bar{k}}-1\right)+(1-\alpha)\left(\frac{n_{t}}{\bar{n}}-1\right)\right], \\
& r_{t}-\bar{r}=r_{k, t}-\bar{r}_{k} .
\end{aligned}
$$

The linearized output and capital accumulation equations are

$$
\begin{aligned}
& y_{t}-\bar{y}=\bar{y}\left[\left(\frac{v_{t}}{\bar{v}}-1\right)+\alpha\left(\frac{k_{t}}{\bar{k}}-1\right)+(1-\alpha)\left(\frac{n_{t}}{\bar{n}}-1\right)\right], \\
& k_{t+1}-\bar{k}=\left(y_{t}-\bar{y}\right)-\left(c_{t}-\bar{c}\right)-\left(g_{t}-\bar{g}\right)+(1-\delta)\left(k_{t}-\bar{k}\right) .
\end{aligned}
$$

The equations giving the steady state are

$$
\begin{aligned}
& \bar{r}=1-\delta+\bar{r}_{k}=\beta^{-1}, \\
& \bar{c}=\bar{v} \bar{k}^{\alpha} \bar{n}^{1-\alpha}-\delta \bar{k}-\bar{g}, \\
& \zeta \bar{c}^{\sigma}=\bar{w}(1-\bar{n})^{\epsilon}, \\
& \bar{w}=(1-\alpha) \bar{v}\left(\frac{\bar{k}}{\bar{n}}\right)^{\alpha} \text { and } \quad \bar{r}_{k}=\alpha \bar{v}\left(\frac{\bar{k}}{\bar{n}}\right)^{\alpha-1} .
\end{aligned}
$$

These five equations can be solved simultaneously to yield the steady state values of $\bar{c}, \bar{k}, \bar{n}, \bar{w}$, and $\bar{r}_{k}$ given the value of $\bar{g}$ and the structural parameters $\alpha, \beta, \delta, \zeta, \sigma, \epsilon$.

\section{Appendix B. Details of solutions under learning}

Under learning, agents need to form forecasts of variables without full knowledge of the underlying model parameters. In the basic formulation, announced policy changes are fully credible and, hence, future forecasts of lump-sum taxes are assumed known to them. However, they still need to form forecasts of future wages and rental rates/interest rates in order to determine their consumption choice in (8). In the learning literature, these forecasts depend on the perceived laws of motion (PLMs) of the agents. We initially start with PLMs that correspond to the REE given in (13)-(15) in which wages, and rental rates are estimated on the basis of data on capital stock and technological shock, $k_{t}$ and $v_{t}$. Thus the PLMs (including constants) of the agents are taken to be of the form of Eqs. (18)-(20), where the PLM parameters $b_{k}, a_{k k}, a_{k v}$, etc., will be estimated on the basis of actual data. The final line is the stochastic process for evolution of the (de-meaned) technological shock which is assumed known to the agents (this is without loss of generality).

We will now write these PLMs in deviation form; with deviations under learning taken from the estimated steady state values of capital, wage rate, and rental rate. Define

$$
\begin{aligned}
& \tilde{k}_{t}=k_{t}-\bar{k}_{t}^{e}, \\
& \tilde{r}_{k, t}=r_{k, t}-\bar{r}_{k, t}^{e}, \\
& \tilde{w}_{t}=w_{t}-\bar{w}_{t}^{e},
\end{aligned}
$$


where, for instance, $\tilde{r}_{k, t}$ is the deviation of the rental rate from the steady state rental rate estimated under learning at time $t$ (i.e. $\left.\bar{r}_{k, t}^{e}\right)$.

Using this notation we have

$$
\begin{gathered}
\tilde{k}_{t+1}=a_{k k} \tilde{k}_{t}+a_{k v} \hat{v}_{t}, \\
\tilde{w}_{t}=a_{w k} \tilde{k}_{t}+a_{w v} \hat{v}_{t}, \\
\tilde{r}_{k, t}=a_{r k} \tilde{k}_{t}+a_{r v} \hat{v}_{t},
\end{gathered}
$$

where the estimated steady state values of capital, rental rates, and wages under learning are (omitting the time subscripts on $\bar{k}_{t}^{e}$, etc.)

$$
\begin{aligned}
& \bar{k}^{e}=\frac{b_{k}}{1-a_{k k}}, \\
& \bar{r}_{k}^{e}=b_{r}+a_{r k} \frac{b_{k}}{1-a_{k k}}, \\
& \bar{w}^{e}=b_{w}+a_{w k} \frac{b_{k}}{1-a_{k k}} .
\end{aligned}
$$

Then under learning, the form corresponding to (16) is

$$
\begin{aligned}
& \left(\begin{array}{l}
\tilde{k}_{t+1} \\
\hat{v}_{t+1}
\end{array}\right)=\tilde{B}\left(\begin{array}{l}
\tilde{k}_{t} \\
\hat{v}_{t}
\end{array}\right)+\left(\begin{array}{c}
0 \\
\tilde{u}_{t+1}
\end{array}\right), \\
& \tilde{B}=\left(\begin{array}{cc}
a_{k k} & a_{k v} \\
0 & \rho
\end{array}\right) .
\end{aligned}
$$

Defining $\tilde{x}_{t} \equiv\left(\begin{array}{l}\tilde{k}_{t} \\ \hat{v}_{t}\end{array}\right)$, we have for $j \geq 1$

$$
\tilde{x}_{t+j}^{e}=\tilde{B}^{j} \tilde{x}_{t}
$$

Using the future forecasts of capital stocks from (33), we can in turn obtain the future forecasts of wages and rental rates from (28) and (29) as

$$
\begin{aligned}
& \tilde{w}_{t+j}^{e}=\left(\begin{array}{ll}
a_{w k} & a_{w v}
\end{array}\right) \tilde{B}^{j} \tilde{x}_{t}, \\
& \tilde{r}_{k, t+j}^{e}=\left(\begin{array}{ll}
a_{r k} & a_{r v}
\end{array}\right) \tilde{B}^{j} \tilde{x}_{t} .
\end{aligned}
$$

We linearize (5) around the deterministic steady state $\bar{c}$ and $\bar{r}=\beta^{-1}$

$$
c_{t}-\bar{c}=\hat{E}_{t}\left(c_{t+1}-\bar{C}\right)-\beta \sigma^{-1} \bar{c} \hat{E}_{t}\left(r_{t+1}-\bar{r}\right) \text {. }
$$

As noted in the main text, we assume agents choose the (known) initial steady state as the point around which to linearize. Iterate Eq. (34) forward to get

$$
c_{t}-\bar{c}=\hat{E}_{t}\left(c_{t+j}-\bar{C}\right)-\beta \sigma^{-1} \bar{c} \hat{E}_{t} \sum_{i=1}^{j}\left(r_{t+i}-\bar{r}\right)
$$

which describes current consumption in terms of expected consumption $j$ steps ahead and future short-term interest rates.

Having obtained the future forecasts of wages and interest rates under learning, we reproduce below the linearized consumption function that agents use to determine their current consumption. First recall Eq. (8)

$$
\left(c_{t}-\bar{c}\right) C_{A A}=\bar{a}\left(r_{t}-\bar{r}\right)+\bar{r}\left(a_{t}-\bar{a}\right)-\left(\tau_{h, t}-\bar{\tau}_{h}\right)+C_{w w}\left(w_{t}-\bar{w}\right)+S 1_{t}^{e}+S 2_{t}^{e},
$$

where $\bar{r}=\beta^{-1}$ in the deterministic steady state and

$$
\begin{aligned}
& C_{A A} \equiv \frac{1}{1-\beta}\left(1+\frac{\sigma}{\epsilon} \zeta^{1 / \epsilon} \bar{w}^{(\epsilon-1) / \epsilon} \bar{C}^{(\sigma / \epsilon)-1}\right), \\
& C_{w w} \equiv 1-\frac{\epsilon-1}{\epsilon} \zeta^{1 / \epsilon} \bar{c}^{\sigma / \epsilon} \bar{w}^{-1 / \epsilon} .
\end{aligned}
$$

$S 1_{t}^{e}$ in (35) is defined as

$$
\begin{aligned}
& S 1_{t}^{e} \equiv-S_{A} S r_{t}^{e}, \\
& S_{A}=\bar{w}-\zeta^{1 / \epsilon} \bar{c}^{\sigma / \epsilon} \bar{w}^{(\epsilon-1) / \epsilon}-\bar{c}-\bar{\tau}_{h},
\end{aligned}
$$


and $S 2_{t}^{e}$ is defined as

$$
S 2_{t}^{e}=\sum_{j=1}^{\infty} \bar{r}^{-j}\left[C_{w w}\left(w_{t+j}^{e}-\bar{w}\right)-\left(\tau_{h, t+j}^{e}-\bar{\tau}_{h}\right)-\bar{r}^{-1}\left(\frac{\bar{c}}{\sigma}+\frac{\zeta^{1 / \epsilon} \bar{c}^{\sigma / \epsilon} \bar{w}^{1-(1 / \epsilon)}}{\epsilon}\right) \sum_{i=1}^{j}\left(r_{t+i}^{e}-\bar{r}\right)\right] .
$$

$S 2_{t}^{e}$ can be rewritten as

$$
S 2_{t}^{e}=C_{w w} S w_{t}^{e}-S \tau_{h, t}^{e}-\left(\frac{\bar{c}}{\sigma}+\frac{\zeta^{1 / \epsilon} \bar{c}^{\sigma / \epsilon} \bar{w}^{1-(1 / \epsilon)}}{\epsilon}\right) S r_{t}^{e},
$$

where $S r_{t}^{e}, S \tau_{h, t}^{e}$, and $S w_{t}^{e}$ are given by Eqs. (9), (10), and (11) respectively.

If we combine the expressions in (36) and (38), we can write the consumption function (35) as

$$
\left(c_{t}-\bar{c}\right) C_{A A}=\bar{a}\left(r_{t}-\bar{r}\right)+\bar{r}\left(a_{t}-\bar{a}\right)-\left(\tau_{h, t}-\bar{\tau}_{h}\right)+C_{w w}\left(w_{t}-\bar{w}\right)-\left(S_{A}+\frac{\bar{c}}{\sigma}+\frac{\bar{c}^{\sigma / \epsilon} \zeta^{1 / \epsilon}}{\epsilon} \bar{w}^{1-(1 / \epsilon)}\right) S r_{t}^{e}+C_{w w} S w_{t}^{e}-S \tau_{h, t}^{e}
$$

which is Eq. (8) in the text, with

$$
C_{r r}=S_{A}+\bar{C} \sigma^{-1}+\bar{c}^{\sigma / \epsilon} \zeta^{1 / \epsilon} \epsilon^{-1} \bar{w}^{1-(1 / \epsilon)} .
$$

For the case $\sigma=\epsilon=1$, the linearization coefficients are given by

$$
C_{A A}=(1+\zeta) /(1-\beta), \quad C_{w w}=1 \quad \text { and } \quad C_{r r}=\bar{w}-\bar{\tau}_{h},
$$

and Eq. (8) reduces to

$$
c_{t}-\bar{c}=\frac{1-\beta}{1+\zeta}\left[\bar{a}\left(r_{t}-\bar{r}\right)+\bar{r}\left(a_{t}-\bar{a}\right)-\left(\tau_{h, t}-\bar{\tau}_{h}\right)+\left(w_{t}-\bar{w}\right)-\left(\bar{w}-\bar{\tau}_{h}\right) S r_{t}^{e}+S w_{t}^{e}-S \tau_{h, t}^{e}\right] .
$$

For the calibrations assumed in the figures, $\bar{w}>\bar{\tau}_{h}$, so that increases in $\operatorname{Sr}_{t}^{e}$ and decreases in $S w_{t}^{e}$ reduce current consumption $c_{t}$, as one would expect.

Since announced policy changes are assumed to be credible, future forecasts of taxes $S \tau_{h, t}^{e}$ coincide with the assumed government fiscal rule in the consumption function (8). However, one still needs to obtain analytical expressions for $S w_{t}^{e}$ and $S r_{t}^{e}$ which appear in (8). This is what we do now.

Note that using $r_{t}-\bar{r}=r_{k, t}-\bar{r}_{k}$ along with (26) we obtain

$$
r_{t}-\bar{r}=\tilde{r}_{k, t}+\bar{r}_{k, t}^{e}-\bar{r}_{k},
$$

which after iterating forward gives us

$$
r_{t+i}-\bar{r}=\left(\tilde{r}_{k, t+i}+\bar{r}_{k, t}^{e}-\bar{r}_{k}\right)=\left(\begin{array}{ll}
a_{r k} & a_{r v}
\end{array}\right) \tilde{B}^{i} \tilde{x}_{t}+\left(\bar{r}_{k, t}^{e}-\bar{r}_{k}\right),
$$

since $\bar{r}_{k, t+i}^{e}=\bar{r}_{k, t}^{e}$; i.e. the estimated steady state rental rate $i$ steps ahead is still based on time $t$ data and hence equals the time $t$ estimate $\bar{r}_{k, t}^{e}$ given in (31). We use this to derive $\operatorname{Sr}_{t}^{e}$ below. Observe that

$$
\sum_{i=1}^{j}\left(r_{t+i}^{e}-\bar{r}\right)=\left(\bar{r}_{k, t}^{e}-\bar{r}_{k}\right) j+\left(a_{r k} \quad a_{r v}\right)\left[(I-\tilde{B})^{-1} \tilde{B}-(I-\tilde{B})^{-1} \tilde{B}^{j+1}\right] \tilde{x}_{t}
$$

since

$$
\sum_{i=1}^{j} \tilde{B}^{i}=(I-\tilde{B})^{-1} \tilde{B}-(I-\tilde{B})^{-1} \tilde{B}^{j+1}
$$

Using this $\operatorname{Sr}_{t}^{e}$ is finally obtained as

$$
S r_{t}^{e}=\frac{\beta^{2}}{(1-\beta)^{2}}\left(\bar{r}_{k, t}^{e}-\bar{r}_{k}\right)+\beta^{2}\left(a_{r k} \quad a_{r v}\right)(I-\tilde{B})^{-1} \tilde{B}\left[I(1-\beta)^{-1}-\tilde{B}(I-\beta \tilde{B})^{-1}\right] \tilde{x}_{t} .
$$

Similarly, since

$$
\left(w_{t+i}^{e}-\bar{w}\right)=\left(\bar{w}_{t}^{e}-\bar{w}+w_{t+i}^{e}-\bar{w}_{t}^{e}\right)=\left(\bar{w}_{t}^{e}-\bar{w}\right)+\tilde{w}_{t+i}^{e},
$$

$S w_{t}^{e}$ can be obtained from

$$
\begin{aligned}
S w_{t}^{e} & =\sum_{j=1}^{\infty} \beta^{j}\left(\bar{w}_{t}^{e}-\bar{w}\right)+\sum_{j=1}^{\infty} \beta^{j} \tilde{w}_{t+j} \\
& =\frac{\beta}{1-\beta}\left(\bar{w}_{t}^{e}-\bar{w}\right)+\sum_{j=1}^{\infty} \beta^{j}\left(a_{w k} \quad a_{w v}\right) \tilde{B}^{j} \tilde{x}_{t} \\
& =\frac{\beta}{1-\beta}\left(\bar{w}_{t}^{e}-\bar{w}\right)+\left(\begin{array}{ll}
a_{w k} & \left.a_{w v}\right) \beta \tilde{B}(I-\beta \tilde{B})^{-1} \tilde{x}_{t} .
\end{array}\right.
\end{aligned}
$$


Finally, we give details concerning the initialization of the parameters under RLS learning discussed in Section 3.1. The initial values of all parameter estimates are set to the initial steady state values under RE, i.e.

$$
\begin{aligned}
& \phi_{k, 0}=\left(\begin{array}{c}
b_{k, 0} \\
a_{k k, 0} \\
a_{k v, 0}
\end{array}\right)=\left(\begin{array}{c}
\left(1-\bar{\lambda}_{2}\right) \bar{k} \\
\bar{\lambda}_{2} \\
\bar{f}_{k v}
\end{array}\right), \\
& \phi_{w, 0}=\left(\begin{array}{c}
b_{w, 0} \\
a_{w k, 0} \\
a_{w v, 0}
\end{array}\right)=\left(\begin{array}{c}
\bar{w}-\bar{f}_{w k} \bar{k} \\
\bar{f}_{w k} \\
\bar{f}_{w v}
\end{array}\right), \\
& \phi_{r k, 0}=\left(\begin{array}{c}
b_{r, 0} \\
a_{r k, 0} \\
a_{r v, 0}
\end{array}\right)=\left(\begin{array}{c}
\bar{r}_{k}-\bar{f}_{r k} \bar{k} \\
\bar{f}_{r k} \\
\bar{f}_{r v}
\end{array}\right) .
\end{aligned}
$$

We also initialize the $R$ matrix at the initial steady state. Define the variance/covariance matrix of $\left(\begin{array}{l}\hat{k}_{t} \\ \hat{v}_{t}\end{array}\right)$ as

$$
\operatorname{Cov}(k, v)=\left(\begin{array}{cc}
\bar{\sigma}_{k}^{2} & \bar{\sigma}_{k v} \\
\bar{\sigma}_{k v} & \sigma_{v}^{2}
\end{array}\right),
$$

where $\bar{\sigma}_{k}^{2}, \sigma_{v}^{2}\left(={ }^{-}\left(1-\rho^{2}\right)^{-1} \sigma_{u}^{2}\right)$ are the variances of the steady state capital and technology shock, and $\bar{\sigma}_{k v}$ is the covariance between capital and the shock $v_{t}$ in the initial steady state. Using standard techniques we can obtain these variances using Eqs. (16) and (17) 33

$$
\begin{aligned}
& \operatorname{vec}(\operatorname{Cov}(k, v))=(I-B \otimes B)^{-1} \operatorname{vec}\left(\Omega_{k v}\right), \\
& \Omega_{k v}=\left(\begin{array}{cc}
0 & 0 \\
0 & \sigma_{u}^{2}
\end{array}\right),
\end{aligned}
$$

so that $\bar{\sigma}_{k}^{2}, \bar{\sigma}_{k v}$, and $\sigma_{v}^{2}$ are given by the first, second, and fourth elements of $\operatorname{vec}(\operatorname{Cov}(k, v))$. The second moment matrix of $z_{t}$ can then be initialized as

$$
\bar{R}=\left(\begin{array}{ccc}
1 & \bar{k} & 0 \\
\bar{k} & \bar{k}^{2}+\bar{\sigma}_{k}^{2} & \bar{\sigma}_{k v} \\
0 & \bar{\sigma}_{k v} & \sigma_{v}^{2}
\end{array}\right),
$$

which gives the starting point for the algorithm for RLS learning.

\section{Appendix C. Details of RE solution with policy change}

We obtain the RE solution under a policy change as in Ljungqvist and Sargent (2012, p. 352), to get

$$
\begin{aligned}
& U_{c}\left(c_{t}, n_{t}\right)=\beta E_{t}\left[U_{c}\left(c_{t+1}, n_{t+1}\right)\left\{1+\left(r_{k, t+1}-\delta\right)\right\}\right], \\
& \frac{U_{n}\left(c_{t}, n_{t}\right)}{U_{c}\left(c_{t}, n_{t}\right)}=-w_{t}=-(1-\alpha) v_{t}\left(\frac{k_{t}}{n_{t}}\right)^{\alpha}, \\
& r_{k, t+1}=\alpha v_{t}\left(\frac{n_{t+1}}{k_{t+1}}\right)^{1-\alpha}, \\
& c_{t}=v_{t} k_{t}^{\alpha} n_{t}^{1-\alpha}+(1-\delta) k_{t}-g_{t}-k_{t+1} .
\end{aligned}
$$

We have for the utility function (2)

$$
U_{c}\left(c_{t}, n_{t}\right)=c_{t}^{-\sigma}, \quad U_{n}\left(c_{t}, n_{t}\right)=-\zeta\left(1-n_{t}\right)^{-\epsilon}
$$

\footnotetext{
${ }^{33}$ Here vec denotes the operator that stacks the columns of a matrix into a vector.
} 
and using these, (40) simplifies to

$$
\frac{\zeta C_{t}^{-\sigma}}{\left(1-n_{t}\right)^{\epsilon}}=(1-\alpha) v_{t}\left(\frac{k_{t}}{n_{t}}\right)^{\alpha} \text {. }
$$

Using (42) to eliminate consumption we get

$$
\zeta\left(v_{t} k_{t}^{\alpha} n_{t}^{1-\alpha}+(1-\delta) k_{t}-g_{t}-k_{t+1}\right)^{\sigma}-(1-\alpha) v_{t}\left(\frac{k_{t}}{n_{t}}\right)^{\alpha}\left(1-n_{t}\right)^{\epsilon}=0 .
$$

Under policy changes, this (and all subsequent) equations will be linearized around the final steady state. ${ }^{34}$ Linearizing (43) we get

$$
0=G_{g 0}\left(g_{t}-\bar{g}\right)+G_{k 0}\left(k_{t}-\bar{k}\right)+G_{k 1}\left(k_{t+1}-\bar{k}\right)+G_{n 0}\left(n_{t}-\bar{n}\right)+G_{v 0}\left(v_{t}-\bar{v}\right) .
$$

$G_{k 0}$ denotes the partial derivatives evaluated for capital at the current time period $t$ (e.g. $k_{t}$ ) and $G_{k 1}$ denotes the partial derivatives evaluated for capital at next period $t+1$ (e.g. $k_{t+1}$ ), etc. At the steady state these derivatives are

$$
\begin{aligned}
& G_{k 0}=\zeta \sigma \bar{c}^{\sigma-1}\left(\bar{r}_{k}+1-\delta\right)-(1-\alpha) \bar{r}_{k} \frac{(1-\bar{n})^{\epsilon}}{\bar{n}}, \\
& G_{k 1}=-\zeta \sigma \bar{c}^{\sigma-1}, \\
& G_{n 0}=\zeta \sigma \bar{c}^{\sigma-1} \bar{w}+(1-\alpha) \bar{v} \bar{k}^{\alpha}\left\{\alpha \bar{n}^{-\alpha-1}(1-\bar{n})^{\epsilon}+\epsilon \bar{n}^{-\alpha}(1-\bar{n})^{\epsilon-1}\right\}, \\
& G_{v 0}=\zeta \sigma \bar{c}^{\sigma-1} \bar{k}^{\alpha} \bar{n}^{1-\alpha}-(1-\alpha) \bar{k}^{\alpha} \bar{n}^{-\alpha}(1-\bar{n}) \epsilon, \\
& G_{g 0}=-\zeta \sigma \bar{c}^{\sigma-1}, \\
& G_{\tau n 0}=\bar{w}(1-\bar{n})^{\epsilon} .
\end{aligned}
$$

Eq. (39) on using (42) becomes

$$
\begin{aligned}
\left(v_{t} k_{t}^{\alpha} n_{t}^{1-\alpha}+(1-\delta) k_{t}-g_{t}-k_{t+1}\right)^{-\sigma}= & \beta E_{t}\left[\left\{v_{t+1} k_{t+1}^{\alpha} n_{t+1}^{1-\alpha}+(1-\delta) k_{t+1}-g_{t+1}-k_{t+2}\right\}^{-\sigma}\right. \\
& \left.\times\left\{1+\left(\alpha v_{t+1}\left(\frac{n_{t+1}}{k_{t+1}}\right)^{1-\alpha}-\delta\right)\right\}\right] .
\end{aligned}
$$

We can linearize this to obtain a solution of the form

$$
\begin{aligned}
0= & H_{k 0}\left(k_{t}-\bar{k}\right)+H_{k 1}\left(k_{t+1}-\bar{k}\right)+H_{k 2} E_{t}\left(k_{t+2}-\bar{k}\right)+H_{n 0}\left(n_{t}-\bar{n}\right) \\
& +H_{n 1} E_{t}\left(n_{t+1}-\bar{n}\right)+H_{g 0}\left(g_{t}-\bar{g}\right)+H_{g 1} E_{t}\left(g_{t+1}-\bar{g}\right)+H_{v 0}\left(v_{t}-\bar{v}\right) \\
& +H_{v 1} E_{t}\left(v_{t+1}-\bar{v}\right) .
\end{aligned}
$$

Define the $H$ coefficients here

$$
\begin{aligned}
& H_{k 0}=-\sigma \bar{c}^{-\sigma-1}\left(\bar{r}_{k}+1-\delta\right), \\
& H_{k 1}=\sigma \bar{c}^{-\sigma-1}+\beta \sigma \bar{c}^{-\sigma-1}\left(\bar{r}_{k}+1-\delta\right) \bar{r}+\beta(1-\alpha) \bar{c}^{-\sigma}\left(\alpha \overline{v n}^{1-\alpha} \bar{k}^{\alpha-2}\right), \\
& H_{k 2}=H_{g 1}=-\beta \sigma \bar{c}^{-\sigma-1} \bar{r}=-\sigma \bar{c}^{-\sigma-1}, \\
& H_{n 0}=-\sigma \bar{c}^{-\sigma-1} \bar{w}, \\
& H_{n 1}=\beta \sigma \bar{c}^{-\sigma-1} \overline{w r}-\beta \bar{c}^{-\sigma}\left(\alpha(1-\alpha) \overline{v n}^{-\alpha} \bar{k}^{\alpha-1}\right), \\
& H_{g 0}=\sigma \bar{c}^{-\sigma-1}, \\
& H_{v 0}=-\sigma \bar{c}^{-\sigma-1} \bar{k}^{\alpha} \bar{n}^{1-\alpha}, \\
& H_{v 1}=\beta \sigma \bar{c}^{-\sigma-1} \bar{k}^{\alpha} \bar{n}^{1-\alpha} \bar{r}-\beta \bar{r}_{k} \bar{c}^{-\sigma}, \\
& H_{\tau k 1}=\beta \bar{c}^{-\sigma}\left(\bar{r}_{k}-\delta\right) .
\end{aligned}
$$

From (44) we get

$$
n_{t}-\bar{n}=-G_{n 0}^{-1}\left[G_{g 0}\left(g_{t}-\bar{g}\right)+G_{k 0}\left(k_{t}-\bar{k}\right)+G_{k 1}\left(k_{t+1}-\bar{k}\right)+G_{v 0}\left(v_{t}-\bar{v}\right)\right],
$$

which implies

$$
E_{t}\left[n_{t+1}-\bar{n}\right]=-G_{n 0}^{-1}\left[G_{g 0} E_{t}\left(g_{t+1}-\bar{g}\right)+G_{k 0}\left(k_{t+1}-\bar{k}\right)+G_{k 1} E_{t}\left(k_{t+2}-\bar{k}\right)+G_{v 0} E_{t}\left(v_{t+1}-\bar{v}\right)\right] .
$$

$k_{t+1}$ is known in period $t$, so there is no expectation before this term.

Eqs. (46) and (47) are substituted in (45) to eliminate $n_{t}$ and $n_{t+1}$ which gives an equation involving only the endogenous variable capital stock

$$
0=J_{k 0}\left(k_{t}-\bar{k}\right)+J_{k 1}\left(k_{t+1}-\bar{k}\right)+J_{k 2} E_{t}\left(k_{t+2}-\bar{k}\right)+J_{g 0}\left(g_{t}-\bar{g}\right)+J_{g 1} E_{t}\left(g_{t+1}-\bar{g}\right)+J_{v 0}\left(v_{t}-\bar{v}\right)+J_{v 1} E_{t}\left(v_{t+1}-\bar{v}\right) .
$$

\footnotetext{
${ }^{34}$ For convenience we now use $\bar{g}, \bar{k}$, etc., to denote the final steady state.
} 
Define the coefficients $J$ below

$$
\begin{aligned}
& J_{k 0}=H_{k 0}-H_{n 0} G_{n 0}^{-1} G_{k 0}, \\
& J_{k 1}=H_{k 1}-H_{n 0} G_{n 0}^{-1} G_{k 1}-H_{n 1} G_{n 0}^{-1} G_{k 0}, \\
& J_{k 2}=H_{k 2}-H_{n 1} G_{n 0}^{-1} G_{k 1}, \\
& J_{g 0}=H_{g 0}-H_{n 0} G_{n 0}^{-1} G_{g 0}, \\
& J_{g 1}=H_{g 1}-H_{n 1} G_{n 0}^{-1} G_{g 0}, \\
& J_{v 0}=H_{v 0}-H_{n 0} G_{n 0}^{-1} G_{v 0}, \\
& J_{v 1}=H_{v 1}-H_{n 1} G_{n 0}^{-1} G_{v 0}, \\
& H_{\tau n 0}=-H_{n 0} G_{n 0}^{-1} G_{\tau n 0}, \\
& H_{\tau n 1}=-H_{n 1} G_{n 0}^{-1} G_{\tau n 0},
\end{aligned}
$$

and $H_{\tau k 1}$ is defined after (45).

Eq. (48) is a second order difference equation for $k_{t}$ in terms of the exogenous policy variables $g_{t}$ and the shock $v_{t}$ with a condition for initial capital stock $k_{0}$. The linear approximation to the solution for the equilibrium $k_{t}$ sequence is obtained by solving the stable root backward and the unstable root forward (see [Ljungqvist and Sargent, 2012, Chapter 11] for the details). We finally write (48) as

$$
E_{t}\left(k_{t+2}-\bar{k}\right)+A_{k 1}\left(k_{t+1}-\bar{k}\right)+A_{k 0}\left(k_{t}-\bar{k}\right)=A_{g 0}\left(g_{t}-\bar{g}\right)+A_{g 1} E_{t}\left(g_{t+1}-\bar{g}\right)+A_{v 0}\left(v_{t}-\bar{v}\right)+A_{v 1} E_{t}\left(v_{t+1}-\bar{v}\right),
$$

where

$$
\begin{aligned}
& A_{k 1}=J_{k 1} J_{k 2}^{-1}, A_{k 0}=J_{k 0} J_{k 2}^{-1}, \\
& A_{g 0}=-J_{g 0} J_{k 2}^{-1}, A_{g 1}=-J_{g 1} J_{k 2}^{-1}, \\
& A_{v 0}=-J_{v 0} J_{k 2}^{-1}, A_{v 1}=-J_{v 1} J_{k 2}^{-1}, \\
& A_{\tau k 1}=-H_{\tau k 1} J_{k 2}^{-1}, \\
& A_{\tau n 0}=-H_{\tau n 0} J_{k 2}^{-1}, A_{\tau n 0}=-H_{\tau n 1} J_{k 2}^{-1} .
\end{aligned}
$$

For this model, one can show that

$$
\begin{aligned}
& A_{g 0}=\frac{1}{1+\frac{n_{1}}{d_{1}}}, \quad A_{g 1}=-1, \\
& n_{1}=\alpha \zeta \bar{c}^{\sigma} \bar{k}^{\alpha}(1-\bar{n})^{1-\epsilon}\left(\frac{\bar{n}}{\bar{k}}\right)^{1+\alpha} \bar{n}^{-\alpha}>0, \\
& d_{1}=\beta^{-1}\{(1-\bar{n}) \alpha+\bar{n} \epsilon\}>0,
\end{aligned}
$$

so that $0<A_{g 0}<1$ and hence $A_{g 1}+A_{g 0}<0$.

The government spending process implies $E_{t} g_{t+1}=\bar{g}_{t+1}$. Also given the process for $v_{t}$

$$
E_{t}\left(v_{t+j}-\bar{v}\right)=\rho^{j}\left(v_{t}-\bar{v}\right) .
$$

Assuming

$$
E_{t} k_{t+2}=k_{t+2}+\eta_{t+1}, \quad E_{t} \eta_{t+1}=0,
$$

Eq. (49) becomes

$$
\left(k_{t+2}-\bar{k}\right)+A_{k 1}\left(k_{t+1}-\bar{k}\right)+A_{k 0}\left(k_{t}-\bar{k}\right) \quad=A_{g 0}\left(g_{t}-\bar{g}\right)+A_{g 1}\left(\bar{g}_{t+1}-\bar{g}\right)+A_{v 0}\left(v_{t}-\bar{v}\right)+A_{v 1} \rho\left(v_{t}-\bar{v}\right)-\eta_{t+1} .
$$

The stochastic process (50) can be solved using the techniques in Sargent (1987, p. 393). This yields

$$
\begin{aligned}
k_{t+1}-\bar{k} & =\lambda_{2}\left(k_{t}-\bar{k}\right)-\lambda_{2} A_{k 0}^{-1} \sum_{j=0}^{\infty} \lambda_{1}^{-j} E_{t}\left[A_{g 0}\left(g_{t+j}-\bar{g}\right)+A_{g 1}\left(\bar{g}_{t+j+1}-\bar{g}\right)+\left(A_{v 0}+\rho A_{v 1}\right)\left(v_{t+j}-\bar{v}\right)-\eta_{t+j+1}\right] \\
& =\lambda_{2}\left(k_{t}-\bar{k}\right)-\lambda_{2} A_{k 0}^{-1} \sum_{j=0}^{\infty} \lambda_{1}^{-j} E_{t}\left[A_{g 0}\left(g_{t+j}-\bar{g}\right)+A_{g 1}\left(\bar{g}_{t+j+1}-\bar{g}\right)+\left(A_{v 0}+\rho A_{v 1}\right)\left(v_{t+j}-\bar{v}\right)\right] .
\end{aligned}
$$

This finally gives the stochastic process for capital (using the hatted values for deviations from RE steady state)

$$
\hat{k}_{t+1}=\lambda_{2} \hat{k}_{t}-\lambda_{2} A_{k 0}^{-1} \sum_{j=0}^{\infty} \lambda_{1}^{-j} E_{t}\left[A_{g 0}\left(g_{t+j}-\bar{g}\right)+A_{g 1}\left(\bar{g}_{t+j+1}-\bar{g}\right)+\left(A_{v 0}+\rho A_{v 1}\right) \hat{v}_{t+j} .\right.
$$

Here $\lambda_{1}, \lambda_{2}$ are given by the roots of the quadratic equation (see Ljungqvist and Sargent, 2012, p. 345)

$$
\begin{aligned}
& \lambda^{2}+A_{k 1} \lambda+A_{k 0}=0, \\
& \lambda_{1} \lambda_{2}=A_{k 0},
\end{aligned}
$$

where it is assumed that $\lambda_{1}>1$ and $0<\lambda_{2}<1$. 
We now specialize the analysis and summarize the details for obtaining a linear approximation to the equilibrium

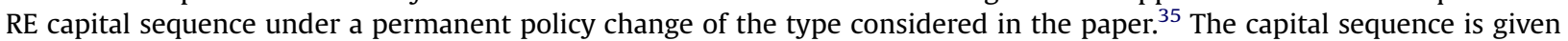
by (51), i.e.

$$
\hat{k}_{t+1}=\lambda_{2} \hat{k}_{t}-\lambda_{2} A_{k 0}^{-1}\left(S_{g}(t)+S_{v}(t)\right)
$$

where

$$
\begin{aligned}
& S_{g}(t) \equiv \sum_{j=0}^{\infty} \lambda_{1}^{-j} E_{t}\left\{A_{g 0}\left(\bar{g}_{t+j}-\bar{g}\right)+A_{g 1}\left(\bar{g}_{t+j+1}-\bar{g}\right)\right\}, \\
& S_{v}(t) \equiv \sum_{j=0}^{\infty} \lambda_{1}^{-j} E_{t}\left(A_{v 0}+\rho A_{v 1}\right) \hat{v}_{t+j}=\left(A_{v 0}+\rho A_{v 1}\right) \sum_{j=0}^{\infty} \lambda_{1}^{-j} \rho^{j} \hat{v}_{t} .
\end{aligned}
$$

We have

$$
\begin{aligned}
& \bar{g}_{t}-\bar{g}= \begin{cases}\bar{g}^{\prime}-\bar{g}, & 1 \leq t<T_{p}, \\
0, & t \geq T_{p},\end{cases} \\
& \bar{g}_{t+j}-\bar{g}= \begin{cases}\bar{g}^{\prime}-\bar{g}, & t+j<T_{p}, \\
0, & t+j \geq T_{p} .\end{cases}
\end{aligned}
$$

One can show that $A_{g 1}=-1$ in (53) which gives us

$$
A_{g 0}\left(\bar{g}_{t+j}-\bar{g}\right)+A_{g 1}\left(\bar{g}_{t+j+1}-\bar{g}\right)= \begin{cases}\left(A_{g 0}-1\right)\left(\bar{g}^{\prime}-\bar{g}\right), & t+j \leq T_{p}-2 \\ A_{g 0}\left(\bar{g}^{\prime}-\bar{g}\right), & t+j=T_{p}-1 \\ 0, & t+j \geq T_{p}\end{cases}
$$

We first compute (54). For all $t \geq 1$, we have

$$
S_{v}(t) \equiv\left(A_{v 0}+\rho A_{v 1}\right) \hat{v}_{t} \sum_{j=0}^{\infty} \lambda_{1}^{-j} \rho^{j}=\frac{\left(A_{v 0}+\rho A_{v 1}\right) \hat{v}_{t}}{1-\frac{\rho}{\lambda_{1}}} .
$$

Then we compute (53). If $1 \leq t \leq T_{p}-2$, we have

$$
S_{g}(t) \equiv \sum_{j=0}^{T_{p}-2-t} \lambda_{1}^{-j}\left(A_{g 0}-1\right)\left(\bar{g}^{\prime}-\bar{g}\right)+\lambda_{1}^{-\left(T_{p}-1-t\right)} A_{g 0}\left(\bar{g}^{\prime}-\bar{g}\right)=\left(\left(A_{g 0}-1\right) \frac{1-\lambda_{1}^{-\left(T_{p}-1-t\right)}}{1-\lambda_{1}^{-1}}+\lambda_{1}^{-\left(T_{p}-1-t\right)} A_{g 0}\right)\left(\bar{g}^{\prime}-\bar{g}\right)
$$

and if $t=T_{p}-1$, then we have

$$
S_{g}(t) \equiv A_{g 0}\left(\bar{g}^{\prime}-\bar{g}\right)
$$

and $S_{g}(t)=0$ for $t \geq T_{p}$.

To summarize

$$
S_{g}(t)= \begin{cases}\left(\left(A_{g 0}-1\right) \frac{1-\lambda_{1}^{-\left(T_{p}-1-t\right)}}{1-\lambda_{1}^{-1}}+\lambda_{1}^{-\left(T_{p}-1-t\right)} A_{g 0}\right)\left(\bar{g}^{\prime}-\bar{g}\right), & 1 \leq t \leq T_{p}-1, \\ 0, & t \geq T_{p} .\end{cases}
$$

Using the formulas in (55) and (56), we can compute the linearized capital dynamics under RE from (52) for a permanent change in government spending under a balanced budget. This is the dynamics which we compare with the learning dynamics.

\section{References}

Aiyagari, R.S., Christiano, L.J., Eichenbaum, M., 1992. The output, employment, and interest rate effects of government consumption. Journal of Monetary Economics 30, 73-86.

Auerbach, A., Gale, W.G., Harris, B.H., 2010. Activist fiscal policy. Journal of Economic Perspectives 24, $141-164$.

Azariadis, C., Bullard, J., Ohanian, L., 2004. Trend-reverting fluctuations in the life-cycle model. Journal of Economic Theory 119, $334-356$.

Baxter, M., King, R.G., 1991. Productive Externalities and Business Cycles," Discussion Paper 53, Institute for Empirical Macroeconomics, Federal Reserve Bank of Minneapolis.

Baxter, M., King, R.G., 1993. Fiscal policy in general equilibrium. The American Economic Review 83, 315-334.

Beaudry, P., Portier, F., 2007. When can changes in expectations cause business cycle fluctuations in neo-classical settings? Journal of Economic Theory 135 , 458-477.

${ }^{35}$ The summations below assume $T_{p} \geq 2$. If $T_{p}=1$, then the policy change is immediate and is termed a surprise (from the point of view of the agents) change which is the benchmark case considered in the paper. Eq. (52) still gives the dynamics of capital for the surprise permanent policy change by setting $S_{g}(t) \equiv 0$. 
Blanchard, O.J., Fischer, S., 1989. Lectures on Macroeconomics. MIT Press, Cambridge, Mass.

Branch, W.A., Evans, G.W., 2006. A simple recursive forecasting model. Economic Letters 91, 158-166.

Branch, W.A., McGough, B., 2011. Heterogeneous expectations, shock amplification and complex dynamics in competitive business cycle models. Economic Theory 47, 395-422.

Campbell, J.Y., 1994. Inspecting the mechanism: an analytical approach to the stochastic growth model. Journal of Monetary Economics 33, 463-506.

Carceles-Poveda, E., Giannitsarou, C., 2008. Asset pricing with adaptive learning. Review of Economic Dynamics 11, 629-651.

Cho, I.-K., Williams, N., Sargent, T.J., 2002. Escaping Nash inflation. Review of Economic Studies 69, 1-40.

Ellison, M., Yates, T., 2007. Escaping volatile inflation. Journal of Money, Credit and Banking 39, 981-993.

Eusepi, S., Preston, B., 2010. Central Bank communication and expectations stabilization. American Economic Journal: Macroeconomics 2, 235-271.

Eusepi, S., Preston, B., 2011. Expectations, learning and business cycle fluctuations. American Economic Review 101, $2844-2872$.

Evans, G.W., Honkapohja, S., 1998. Economic dynamics with learning: new stability results. Review of Economic Studies 65, 23-44.

Evans, G.W., Honkapohja, S., 2001. Learning and Expectations in Macroeconomics. Princeton University Press, Princeton, New Jersey.

Evans, G.W., Honkapohja, S., 2013. Learning as a Rational Foundation for Macroeconomics and Finance. In: Frydman, R., Phelps, E. (Eds.), Rethinking Expectations: The Way Forward for Macroeconomics. Princeton University Press, pp. 68-111 (Chapter 2).

Evans, G.W., Honkapohja, S., Marimon, R., 2001. Convergence in monetary inflation models with heterogeneous learning rules. Macroeconomic Dynamics 5 , $1-31$.

Evans, G.W., Honkapohja, S., Mitra, K., 2009. Anticipated fiscal policy and learning. Journal of Monetary Economics 56, $930-953$.

Evans, G.W., Honkapohja, S., Mitra, K., 2012. Does Ricardian equivalence hold when expectations are not rational? Journal of Money, Credit and Banking 44, 1259-1283.

Farmer, R.E., 1999. The Macroeconomics of Self-Fulfilling Prophecies, second edition MIT Press, Cambridge, Mass.

Farmer, R.E., Guo, J.-T., 1994. Real business cycles and the animal spirits hypothesis. The Journal of Economic Theory 63, $42-72$.

Giannitsarou, C., 2006. Supply-side reforms and learning dynamics. Journal of Monetary Economics 53, $291-309$.

Guesnerie, R., 2002. Anchoring economic predictions in common knowledge. Econometrica 70, 439-480.

Heijdra, B.J., 2009. Foundations of Modern Macroeconomics. Oxford University Press, Oxford.

House, C.L., Shapiro, M.D., 2006. Phased-in tax cuts and economic activity. The American Economic Review 96, 1835-1849.

Huang, K., Liu, Z., Zha, T., 2009. Learning, adaptive expectations and technology shocks. Economic Journal 119, $377-405$.

Jaimovich, N., Rebelo, S., 2009. Can news about the future drive the business cycle? American Economic Review 99, $1097-1118$.

King, R.G., Plosser, C.I., Rebello, S.T., 1988. Production, growth and business cycles. Journal of Monetary Economics 21, $195-232$.

King, R.G., Rebello, S.T., 1999. Resuscitating real business cycles. In: Taylor, J., Woodford, M. (Eds.), Handbook of Macroeconomics, vol. 1. Elsevier, Amsterdam, pp. 927-1007.

Leeper, E.M., Richter, A.W., Walker, T.B., 2012. Quantitative effects of fiscal foresight. American Economic Journal: Economic Policy 4, 115-144.

Leeper, E.M., Traum, N., Walker, T.B., 2011. Clearing Up the Fiscal Multiplier Morass. Mimeo.

Leeper, E.M., Walker, T.B., Yang, S.-C.S., 2008. Fiscal Foresight: Analytics and Econometrics. NBER working Paper 14028.

Ljungqvist, L., Sargent, T.J., 2012. Recursive Macroeconomic Theory, third edition MIT Press, Cambridge, MA.

Long Jr., J.B., Plosser, C.I., 1983. Real business cycles. Journal of Political Economy 91, 39-69.

Marcet, A., Nicolini, J.P., 2003. Recurrent hyperinflations and learning. American Economic Review 93, 1476-1498.

McCallum, B.T., 1989. Real Business Cycles. In: Barro, R.J. (Ed.), Modern Business Cycle Theory. Harvard University Press, Cambridge, MA, pp. 16-50.

McGough, B., 2006. Shocking escapes. Economic Journal 116, 507-528.

Mertens, K., Ravn, M.O., 2011. Understanding the aggregate effects of anticipated and unanticipated policy shocks. Review of Economic Dynamics 14, 27-54.

Milani, F., 2007. Expectations, learning and macroeconomic persistence. Journal of Monetary Economics 54, $2065-2082$.

Milani, F., 2011. Expectation shocks and learning as drivers of the business cycle. Economic Journal 121, 379-401.

Mitra, K., Evans, G.W., Honkapohja, S., 2011. Policy Change and Learning in the RBC Model. Working Paper 1111, Centre for Dynamic Macroeconomic Analysis, University of St Andrews.

Mitra, K., Evans, G.W., Honkapohja, S., 2012. Fiscal Policy and Learning. Working Paper 1202, Centre for Dynamic Macroeconomic Analysis, University of St. Andrews.

Orphanides, A., Williams, J.C., 2007. Robust monetary policy with imperfect knowledge. Journal of Monetary Economics 54, 1406-1435.

Preston, B., 2006. Adaptive learning, forecast-based instrument rules and monetary policy. Journal of Monetary Economics 53, 507-535.

Ramey, V.A., 2009. Identifying Government Spending Shocks: It's All In The Timing. NBER Working Paper 15464.

Ramey, V.A., 2011. Identifying government spending shocks: it's all in the timing. The Quarterly Journal of Economics 126, 1-50.

Romer, D., 2011. Advanced Macroeconomics, fourth edition McGraw-Hill, The McGraw-Hill Companies, New York.

Sargent, T.J., 1987. Macroeconomic Theory, second edition Academic Press, New York.

Sargent, T.J., 1993. Bounded Rationality in Macroeconomics. Oxford University Press, Oxford.

Sargent, T.J., 1999. The Conquest of American Inflation. Princeton University Press, Princeton NJ.

Sargent, T.J., 2008. Evolution and Intelligent Design. American Economic Review 98, 5-37.

Sargent, T.J., Wallace, N., 1973. The stability of models of money and growth with perfect foresight. Econometrica 41, $1043-1048$.

Schmitt-Grohe, S., Uribe, M., 2012. What's news in business cycles. Econometrica 80, 2733-2764.

Strulik, H., Trimborn, T., 2010. Anticipated tax reforms and temporary tax cuts: a general equilibrium analysis. Journal of Economic Dynamics and Control 34, 2141-2158

Yang, S.-C.S., 2005. Quantifying tax effects under policy foresight. Journal of Monetary Economics 52, 1557-1568. 